Check for updates

Cite this: RSC Adv., 2017, 7, 49903

Accepted 17th October 2017

DOI: $10.1039 / \mathrm{c} 7 \mathrm{ra} 07567 \mathrm{~g}$

rsc.li/rsc-advances

\title{
Concise synthesis of the pyruvic acid acetal containing pentasaccharide repeating unit of the cell wall O-antigen of Escherichia coli 0156 $\uparrow$
}

\author{
Anshupriya Si and Anup Kumar Misra (D) * \\ An elegant convergent synthetic strategy has been developed for the preparation of the 4,6-O-(R)-pyruvate \\ acetal containing pentasaccharide repeating unit of the cell wall O-antigen of Escherichia coli O156 using \\ stereoselective [2 + 3] block glycosylation. Stereoselective 1,2-cis glycosylation of the judiciously \\ functionalized monosaccharide intermediates led to the formation of the desired pentasaccharide in \\ satisfactory yield.
}

\section{Introduction}

Diarrhoeal epidemic due to bacterial infections is a serious health concern worldwide. ${ }^{1}$ A significant number of people are suffering from gastrointestinal infections in developing countries where adequate sanitation is lacking. ${ }^{2}$ Diarrhoea is one of the leading causes of death in children, elderly people and patients with insufficient immunity., Enteric infections and colitis are also commonly found in developed countries due to the consumption of uncooked or semi cooked foods. ${ }^{5}$ Enteropathogenic Escherichia coli (E. coli) strains are the predominant bacteria causing gastrointestinal disorder among the various microorganisms responsible for the diarrhoea. ${ }^{6} E$. coli is a commensal organism present in the gastrointestinal microflora in human. ${ }^{7}$ In an immunocompromised state of the host they become virulent and cause a number of infections such as diarrhoea,${ }^{8}$ urinary tract infection, ${ }^{9}$ hemorrhagic colitis (HC), ${ }^{\mathbf{1 0}}$ hemolytic uremic syndrome (HUS), ${ }^{11}$ septicaemia ${ }^{12}$ etc. E. coli strains causing enteric infections are classified into several subclasses based on their mode of infections, ${ }^{13}$ which include (a) enteropathogenic E. coli (EPEC); (b) enterohemorrhagic $E$. coli (EHEC); (c) enteroinvasive E. coli (EIEC); (d) enterotoxigenic E. coli (ETEC); (e) enteroaggregative E. coli (EAEC); (f) diffusely adherent $E$. coli (DAEC). EHEC strains are also termed as Shigatoxin producing $E$. coli (STEC) because of their capability to secrete Shiga-like toxin during the early stage of infections. ${ }^{14} E$. coli strains belong to the subclass EHEC or STEC have been associated with a number of deadly gastrointestinal outbreaks in the developed countries. ${ }^{15}$ One of the frequently found EHEC strain is E. coli O157, which was the causative agent for several diarrhoeal outbreaks in Europe and America. ${ }^{16}$ Besides, E. coli

Bose Institute, Division of Molecular Medicine, P-1/12, C.I.T. Scheme VII M, Kolkata 700054, India. E-mail: akmisra69@gmail.com; Fax: +91-33-2355-3886

$\uparrow$ Electronic supplementary information (ESI) available: Copies of the NMR spectra of compounds $1,7, \mathbf{8}, \mathbf{9}, \mathbf{1 1}, \mathbf{1 2}, \mathbf{1 3}, \mathbf{1 5}$. See DOI: $10.1039 / \mathrm{c} 7 \mathrm{ra07567g}$
O157, several E. coli strains associated with diarrheal diseases have been identified and characterized which belong to the EHEC category such as E. coli O4, O26, O55, O103, O111, O145, O150, O156 etc. ${ }^{17}$ The cell walls of the pathogenic bacteria are highly associated with their virulent properties. The $O$-polysaccharides or O-antigens, a component of bacterial cell wall endotoxins play vital role at the initial stage of bacterial infections to the host. ${ }^{18}$ Therefore, the O-antigen of the bacterial cell wall is useful tool for the development of therapeutics for the eradication of the bacterial infections. Conventionally, several polysaccharide vaccines have been developed in the past using cell wall polysaccharides of pathogenic bacterial strains. ${ }^{19}$ Later the polysaccharide vaccines have been replaced by more efficacious glycoconjugate vaccines based on the cell wall O-antigens. ${ }^{20}$ Duan et al. ${ }^{21}$ reported the structure of the pyruvic acid acetal containing pentasaccharide repeating unit of the cell wall O-antigen of E. coli O156, which belongs to STEC class and responsible for a number of EHEC associated diseases in humans. Therefore, it would be pertinent to develop vaccine candidates against $E$. coli $\mathrm{O} 156$ using the O-antigen. However, isolation of polysaccharides from the natural bacterial sources is quite troublesome and suffers from a number of shortcomings such as, handling of live bacterial strain, cannot produce substantial quantities of polysaccharides at a time, lack of adequate purity and free from biological impurities, lack of homogeneity in the isolated polysaccharide fragments etc. Therefore, it is preferable to develop concise synthetic strategies for the chemical synthesis of the oligosaccharide repeating units with precise structures devoid of above mentioned shortcomings. ${ }^{22}$ Recently, glycoconjugate vaccines developed using synthetic oligosaccharides have been proved to be equally or better immunogenic than the conventional polysaccharide conjugate vaccines. ${ }^{23}$ The synthetic oligosaccharides can be conveniently functionalized according to the requirement of the conjugation with appropriate proteins to furnish glycoconjugates with higher better homogeneity. In this context, it 
was decided to develop a convergent synthetic strategy for the synthesis of the pyruvic acid acetal containing pentasaccharide repeating unit of the O-antigen of E. coli $\mathrm{O} 156$ as its 2-aminoethyl glycoside. The 2-aminoethyl group at the reducing end of the pentasaccharide could be useful in conjugating the glycan moiety with an appropriate protein or aglycon to prepare glycoconjugate derivatives. A concise chemical synthesis of the pentasaccharide repeating unit of the O-antigen of E. coli O156 is reported herein.

\section{Results and discussion}

The target pentasaccharide containing a pyruvic acid acetal has been synthesized as its 2-aminoethyl glycoside using a stereoselective convergent $[2+3]$ block glycosylation strategy. Presence of a number of 1,2-cis glycosidic linkages present pentasaccharide poses extra challenges for its synthesis. The key features of the synthetic strategy are (a) stereoselective 1,2cis glycosylation using either thioglycoside or glycosyl trichloroacetimidate derivatives as glycosyl donors; (b) use of perchloric acid supported over silica gel $\left(\mathrm{HClO}_{4}-\mathrm{SiO}_{2}\right)^{24}$ as a solid acid catalyst; (c) activation of thioglycosides using a combination of $\mathrm{N}$-iodosuccinimide (NIS) and $\mathrm{HClO}_{4}-\mathrm{SiO}_{2}{ }^{25}$ (d) activation of glycosyl trichloroacetimidate using $\mathrm{HClO}_{4}$ $\mathrm{SiO}_{2}{ }^{26}$ (e) preparation of pyruvate acetal using pyruvate dithioacetal; ${ }^{27}$ (f) achievements of 1,2-cis glycosylated products in high yield. A set of suitably functionalized monosaccharide intermediates $2,^{28} 3,,^{29} 4,^{30} 5$ (ref. 31) and 6 (ref. 32) were prepared from the commercially available reducing sugars using literature reported reaction methodologies (Fig. 1).

Stereoselective 1,2-cis-glycosylation of compound 2 and L-fucosyl thioglycoside 3 in the presence of a combination ${ }^{25}$ of NIS and $\mathrm{HClO}_{4}-\mathrm{SiO}_{2}$ in a mixed solvent of $\mathrm{CH}_{2} \mathrm{Cl}_{2}-\mathrm{Et}_{2} \mathrm{O}(1: 5)$ furnished disaccharide derivative 7 in $70 \%$ yield, which was characterized by its NMR spectral analysis [signals at $\delta 5.34(\mathrm{~d}$, $\left.J=8.5 \mathrm{~Hz}, \mathrm{H}-1_{\mathrm{A}}\right), 4.84\left(\mathrm{~d}, J=3.5 \mathrm{~Hz}, \mathrm{H}-1_{\mathrm{B}}\right)$ in ${ }^{1} \mathrm{H}$ NMR and $\delta 99.1$ $\left(C-1_{A}\right)$, $98.7\left(C-1_{B}\right)$ in ${ }^{13} C$ NMR spectra]. Treatment of compound 7 with sodium methoxide ${ }^{33}$ resulted in the formation of the

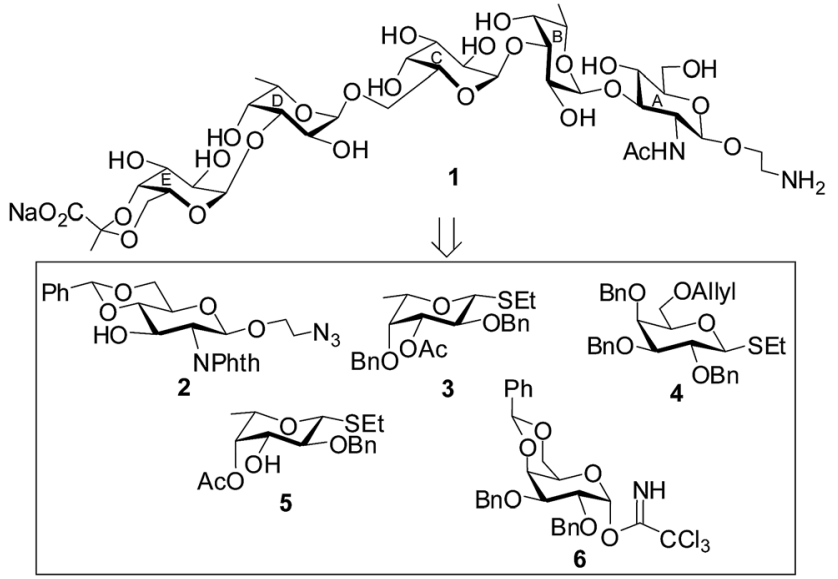

Fig. 1 Structure of the synthesized pentasaccharide containing pyruvic acid acetal and its synthetic intermediates. disaccharide acceptor $\mathbf{8}$ after de-O-acetylation in 93\% yield. Stereoselective 1,2-cis glycosylation of compound 8 with D-galactosyl thioglycoside 4 using NIS and $\mathrm{HClO}_{4}-\mathrm{SiO}_{2}$ combination ${ }^{25}$ in a mixed solvent of $\mathrm{CH}_{2} \mathrm{Cl}_{2}-\mathrm{Et}_{2} \mathrm{O}(1: 3)$ furnished trisaccharide derivative 9 in $76 \%$ yield together with the minor quantity ( $\sim 5 \%)$ of its 1,2-trans glycoside, which was separated by column chromatography. The newly formed glycosyl linkage in compound 9 was confirmed by its NMR spectral analysis [signals at $\delta 5.33\left(\mathrm{~d}, J=8.5 \mathrm{~Hz}, \mathrm{H}-1_{\mathrm{A}}\right), 4.85\left(\mathrm{~d}, J=3.5 \mathrm{~Hz}, \mathrm{H}-1_{\mathrm{B}}\right)$, $4.65\left(\mathrm{~d}, J=3.0 \mathrm{~Hz}, \mathrm{H}-1_{\mathrm{C}}\right)$ in ${ }^{1} \mathrm{H}$ NMR and $\delta 99.5\left(\mathrm{C}-1_{\mathrm{C}}\right), 99.0$ $\left(\mathrm{C}-1_{\mathrm{A}}\right), 98.4\left(\mathrm{C}-1_{\mathrm{B}}\right)$ in ${ }^{13} \mathrm{C}$ NMR spectra]. Treatment of compound 9 with acetic anhydride in the presence of $\mathrm{HClO}_{4}-\mathrm{SiO}_{2}$ resulted in the formation of compound $\mathbf{1 0}$ in $88 \%$ yield by direct conversion of the benzylidene acetal into di-O-acetylated derivative. ${ }^{34}$ The allyl ether of compound $\mathbf{1 0}$ was removed by the treatment with palladium chloride ${ }^{35}$ to furnish trisaccharide acceptor 11 in $72 \%$ yield. NMR spectral analysis of compound 11 supported its formation [signals at $\delta 5.44(\mathrm{~d}, J=8.0 \mathrm{~Hz}$, $\left.\mathrm{H}-1_{\mathrm{A}}\right), 4.50\left(\mathrm{~d}, J=3.0 \mathrm{~Hz}, \mathrm{H}-1_{\mathrm{B}}\right), 4.30\left(\mathrm{~d}, J=3.0 \mathrm{~Hz}, \mathrm{H}-1_{\mathrm{C}}\right)$ in ${ }^{1} \mathrm{H}$ NMR and $\delta 101.3\left(\mathrm{C}-1_{\mathrm{C}}\right), 98.6\left(\mathrm{C}-1_{\mathrm{A}}\right), 95.9\left(\mathrm{C}-1_{\mathrm{B}}\right)$ in ${ }^{13} \mathrm{C}$ NMR spectra] (Scheme 1).

In another experiment, stereoselective orthogonal 1,2-cisglycosylation of L-fucosyl thioglycoside acceptor 5 with D-galactosyl trichloroacetimidate donor 6 in the presence of $\mathrm{HClO}_{4}-$ $\mathrm{SiO}_{2}$ (ref. 26) in $\mathrm{CH}_{2} \mathrm{Cl}_{2}-\mathrm{Et}_{2} \mathrm{O}(1: 3)$ resulted in the formation of compound 12 in 74\% yield. The anomeric thioether present in the acceptor was unaffected under the reaction condition maintaining the orthogonality ${ }^{36}$ of the reaction. The formation the 1,2-cis-glycosylated disaccharide thioglycoside derivative 12 was confirmed from its NMR spectral analysis [signals at $\delta 5.44$ (d, $\left.J=3.5 \mathrm{~Hz}, \mathrm{H}-1_{\mathrm{E}}\right), 4.44$ (d, $\left.J=9.5 \mathrm{~Hz}, \mathrm{H}-1_{\mathrm{D}}\right)$ in ${ }^{1} \mathrm{H}$ NMR and $\delta 100.0\left(\mathrm{C}-1_{\mathrm{E}}\right), 85.2\left(\mathrm{C}-1_{\mathrm{D}}\right)$ in ${ }^{13} \mathrm{C}$ NMR spectra] (Scheme 2).

The disaccharide thioglycoside donor $\mathbf{1 2}$ and trisaccharide acceptor 11 was allowed to couple in a 1,2-cis stereoselective manner in the presence of a combination ${ }^{25}$ of NIS and $\mathrm{HClO}_{4}$ $\mathrm{SiO}_{2}$ in $\mathrm{CH}_{2} \mathrm{Cl}_{2}-\mathrm{Et}_{2} \mathrm{O}(1: 4)$ to furnish the pentasaccharide derivative 13 in $72 \%$ yield. The formation of compound 13 was confirmed from its NMR spectral analysis [signals at $\delta 5.57(\mathrm{~d}$, $\left.J=3.5 \mathrm{~Hz}, \mathrm{H}-1_{\mathrm{D}}\right), 5.42\left(\mathrm{~d}, J=7.5 \mathrm{~Hz}, \mathrm{H}-1_{\mathrm{A}}\right), 4.86(\mathrm{~d}, J=3.0 \mathrm{~Hz}$, $\left.\mathrm{H}-1_{\mathrm{E}}\right), 4.65\left(\mathrm{~d}, J=3.0 \mathrm{~Hz}, \mathrm{H}-1_{\mathrm{B}}\right), 4.23\left(\mathrm{~d}, J=3.0 \mathrm{~Hz}, \mathrm{H}-1_{\mathrm{C}}\right)$ in ${ }^{1} \mathrm{H}$ $\mathrm{NMR}$ and $\delta 102.4\left(J_{\mathrm{C}-1 / \mathrm{H}-1}=168 \mathrm{~Hz}, \mathrm{C}-1_{\mathrm{C}}\right), 99.03\left(J_{\mathrm{C}-1 / \mathrm{H}-1}=\right.$ $\left.170 \mathrm{~Hz}, \mathrm{C}-1_{\mathrm{D}}\right), 98.3\left(J_{\mathrm{C}-1 / \mathrm{H}-1}=168 \mathrm{~Hz}, \mathrm{C}-1_{\mathrm{E}}\right), 98.2\left(J_{\mathrm{C}-1 / \mathrm{H}-1}=\right.$ $\left.170 \mathrm{~Hz}, \mathrm{C}-1_{\mathrm{B}}\right), 97.5\left(J_{\mathrm{C}-1 / \mathrm{H}-1}=158 \mathrm{~Hz}, \mathrm{C}-1_{\mathrm{A}}\right){ }^{13} \mathrm{C}$ NMR spectra]. The presence of four $\alpha$-glycosyl linkages and one $\beta$-glycosyl linkage in the molecule was also unambiguously confirmed from the $\mathrm{C}-1 / \mathrm{H}-1$ coupling constants $\left(J_{\mathrm{C}-1 / \mathrm{H}-1}\right)$ of the monosaccharide moieties in ${ }^{1} \mathrm{H}$ coupled ${ }^{13} \mathrm{C}$ NMR spectrum. ${ }^{37,38}$ The benzylidene acetal in the terminal D-galactosyl moiety in compound 13 was smoothly removed by the treatment ${ }^{34}$ with $\mathrm{HClO}_{4}-\mathrm{SiO}_{2}$ at room temperature to give the diol derivative 14 in $82 \%$ yield. Compound 14 was allowed to react with methyl 2,2di(ethylthio)propionate ${ }^{39}$ in the presence of a combination of NIS and triflic acid (TfOH) ${ }^{27}$ to furnish compound 15 in 68\% yield containing the desired 4,6- $(R)$-pyruvate acetal in the D-galactosyl moiety, which was confirmed from its NMR spectral analysis [signals at $\delta 5.55\left(\mathrm{~d}, J=3.5 \mathrm{~Hz}, \mathrm{H}-1_{\mathrm{D}}\right), 5.42(\mathrm{~d}, J=$ $\left.8.0 \mathrm{~Hz}, \mathrm{H}-1_{\mathrm{A}}\right), 4.89$ (d, $\left.J=3.0 \mathrm{~Hz}, \mathrm{H}-1_{\mathrm{E}}\right), 4.67$ (d, $J=3.5 \mathrm{~Hz}, \mathrm{H}-1_{\mathrm{B}}$ ), 


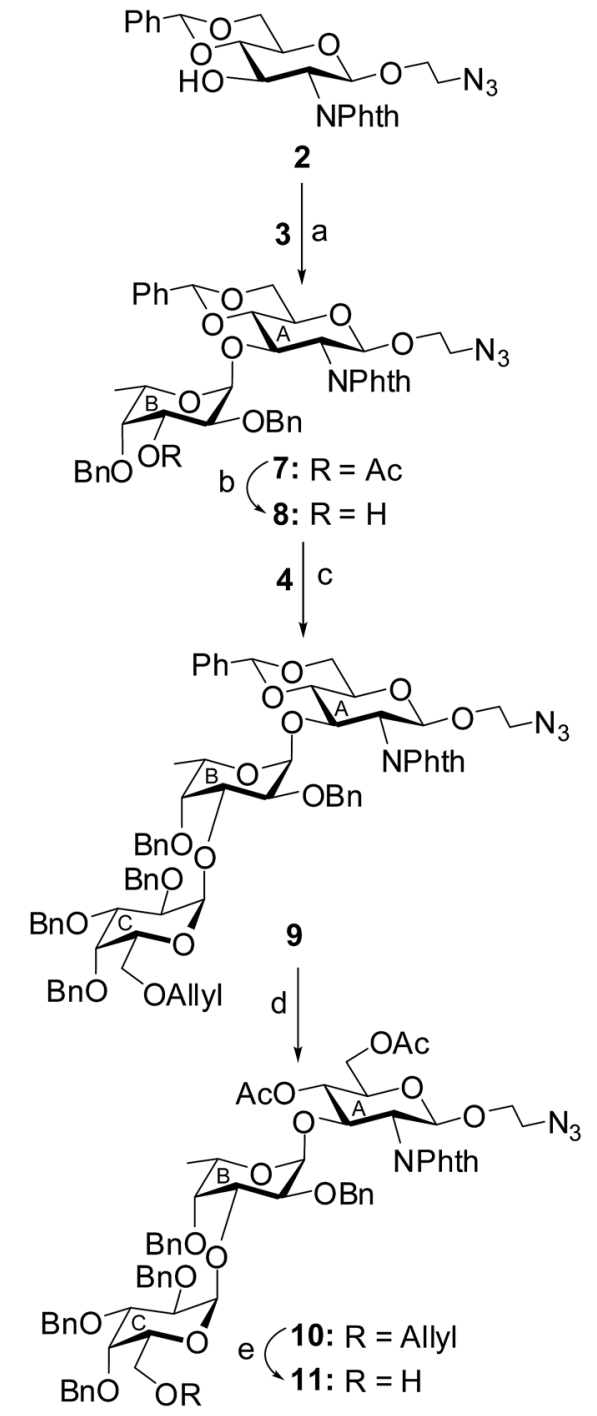

Scheme 1 Reagents: (a) NIS, $\mathrm{HClO}_{4}-\mathrm{SiO}_{2}, \mathrm{MS} 4 \AA \mathrm{CH}_{2} \mathrm{Cl}_{2}-\mathrm{Et}_{2} \mathrm{O}(1: 5$, v/v), $0{ }^{\circ} \mathrm{C}, 15 \mathrm{~min}, 70 \%$; (b) $\mathrm{CH}_{3} \mathrm{ONa}, \mathrm{CH}_{3} \mathrm{OH}$, room temperature, $3 \mathrm{~h}$, 93\%; (c) $\mathrm{NIS}, \mathrm{HClO}_{4}-\mathrm{SiO}_{2}, \mathrm{MS} 4 \AA, \mathrm{CH}_{2} \mathrm{Cl}_{2}-\mathrm{Et}_{2} \mathrm{O}(1: 3, \mathrm{v} / \mathrm{v}),-10{ }^{\circ} \mathrm{C}$, $25 \mathrm{~min}, 76 \%$; (d) acetic anhydride, $\mathrm{HClO}_{4}-\mathrm{SiO}_{2}$, room temperature, 20 min, 88\%; (e) $\mathrm{PdCl}_{2}, \mathrm{CH}_{3} \mathrm{OH}, 0{ }^{\circ} \mathrm{C}, 1 \mathrm{~h}, 76 \%$.

$4.28\left(\mathrm{~d}, J=3.5 \mathrm{~Hz}, \mathrm{H}-1_{\mathrm{C}}\right)$ in ${ }^{1} \mathrm{H}$ NMR and $\delta 102.4\left(\mathrm{C}-1_{\mathrm{C}}\right), 99.08(\mathrm{C}-$ $\left.1_{\mathrm{D}}\right), 98.8\left(\mathrm{CCH}_{3}\right), 98.3\left(\mathrm{C}-1_{\mathrm{E}}\right), 98.1\left(\mathrm{C}-1_{\mathrm{B}}\right), 97.5\left(\mathrm{C}-1_{\mathrm{A}}\right), 26.0\left(\mathrm{CCH}_{3}\right)$ in ${ }^{13} \mathrm{C}$ NMR spectra]. Appearance of the methyl carbon of the

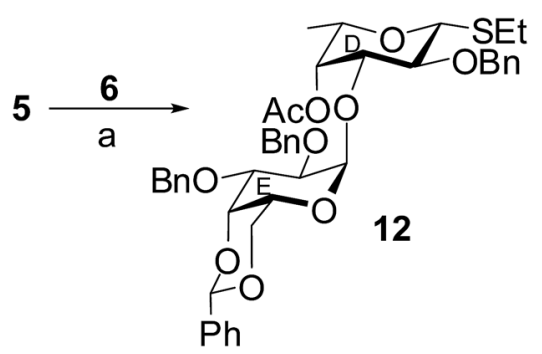

Scheme 2 Reagents: (a) $\mathrm{HClO}_{4}-\mathrm{SiO}_{2}, \mathrm{MS} 4 \AA \mathrm{CH}_{2} \mathrm{Cl}_{2}-\mathrm{Et}_{2} \mathrm{O}(1: 3, \mathrm{v} / \mathrm{v})$, $-10{ }^{\circ} \mathrm{C}, 2 \mathrm{~h}, 74 \%$. pyruvate acetal at $\delta 26 \mathrm{ppm}$ in ${ }^{13} \mathrm{C}$ NMR spectrum confirmed the formation of the 4,6- $(R)$-pyruvate acetal. ${ }^{40}$ Finally, compound 15 was subjected to a sequence of reactions involving (a) treatment with ethylenediamine to remove the $N$-phthaloyl group; ${ }^{\mathbf{4 1}}$ (b) acetylation of the newly generated amine; (c) removal of the benzyl ethers using hydrogenolysis over $\mathrm{Pd}(\mathrm{OH})_{2}-\mathrm{C}^{\mathbf{4 2}}$ (d) removal of the $O$-acetyl group followed by hydrolysis of the methyl ester in the pyruvate moiety using sodium methoxide to furnish the desired pentasaccharide 1 in $54 \%$ over all yield. The NMR spectral analysis of compound 1 supported the formation of the desired compound [signals at $\delta 5.08\left(\mathrm{~d}, J=3.5 \mathrm{~Hz}, \mathrm{H}-1_{\mathrm{E}}\right)$, $5.05\left(\mathrm{~d}, J=4.0 \mathrm{~Hz}, \mathrm{H}-1_{\mathrm{C}}\right), 4.89$ (d, $\left.J=3.5 \mathrm{~Hz}, \mathrm{H}-1_{\mathrm{B}}\right), 4.78$ (d, $J=$ $\left.4.0 \mathrm{~Hz}, \mathrm{H}-1_{\mathrm{D}}\right), 4.41$ (d, $\left.J=8.5 \mathrm{~Hz}, \mathrm{H}-1_{\mathrm{A}}\right)$ in ${ }^{1} \mathrm{H}$ NMR and $\delta 101.5$

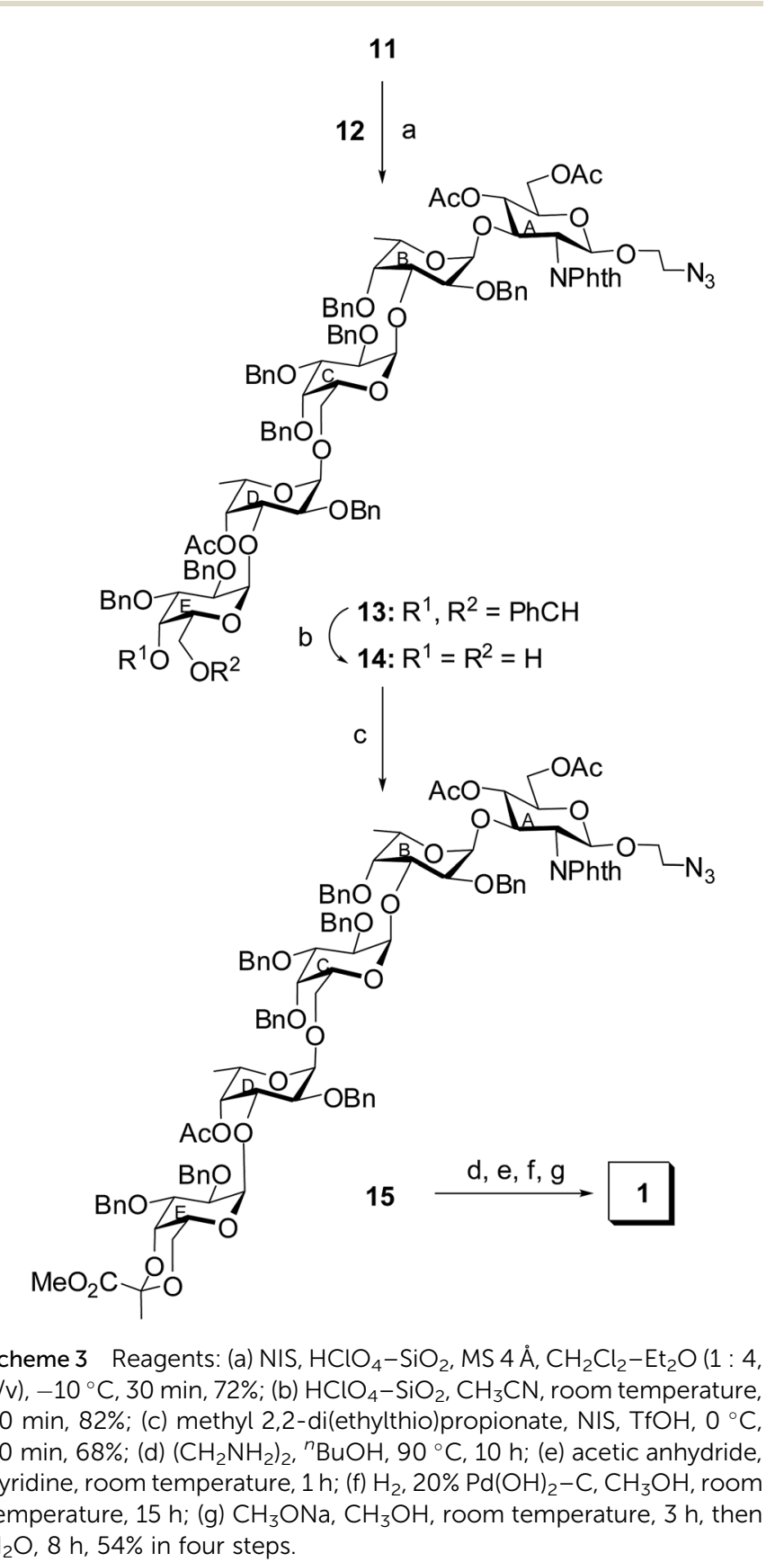


$\left(\mathrm{C}-1_{\mathrm{A}}\right), 100.7\left(2 \mathrm{C}, \mathrm{C}-1_{\mathrm{C}}, \mathrm{C}-1_{\mathrm{E}}\right), 100.6(\mathrm{CCOOH}), 99.8\left(\mathrm{C}-1_{\mathrm{D}}\right), 98.4$ $\left(\mathrm{C}-1_{\mathrm{B}}\right)$ in ${ }^{13} \mathrm{C}$ NMR spectra] (Scheme 3$)$.

\section{Experimental}

\section{General methods}

All reactions were monitored by thin layer chromatography over silica gel coated TLC plates. The spots on TLC were visualized by warming ceric sulphate $\left(2 \% \mathrm{Ce}\left(\mathrm{SO}_{4}\right)_{2}\right.$ in $\left.2 \mathrm{~N} \mathrm{H}_{2} \mathrm{SO}_{4}\right)$ sprayed plates in hot plate. Silica gel 230-400 mesh was used for column chromatography. NMR spectra were recorded on Bruker Avance $500 \mathrm{MHz}$ using $\mathrm{CDCl}_{3}$ as solvent and TMS as internal reference unless stated otherwise. Chemical shift value is expressed in $\delta \mathrm{ppm}$. The complete assignment of proton and carbon spectra was carried out by using a standard set of NMR experiments, e.g. ${ }^{1} \mathrm{H}$ NMR, ${ }^{13} \mathrm{C}$ NMR, ${ }^{13} \mathrm{C}$ DEPT 135, 2D COSY and 2D HSQC etc. MALDI-MS were recorded on a Bruker Daltonics mass spectrometer. Optical rotations were recorded in a Jasco P-2000 spectrometer. Commercially available grades of organic solvents of adequate purity are used in all reactions. $\mathrm{HClO}_{4}-$ $\mathrm{SiO}_{2}$ was prepared following the procedure reported by Chakraborti et al. $^{24}$

\section{2-Azidoethyl $O$-(3-O-acetyl-2,4-di-O-benzyl- $\alpha$-L-fucopyranosyl)- $(1 \rightarrow 3)-2-N$-phthalimido-4,6- $O$-benzylidene-2-deoxy- $\beta$-D- glucopyranoside (7)}

To a solution of compound $2(1.5 \mathrm{~g}, 3.22 \mathrm{mmol})$ and compound $3(1.5 \mathrm{~g}, 3.48 \mathrm{mmol})$ in anhydrous $\mathrm{CH}_{2} \mathrm{Cl}_{2}-\mathrm{Et}_{2} \mathrm{O}(18 \mathrm{~mL}, 1: 5 \mathrm{v} / \mathrm{v})$ was added MS $4 \AA$ ( $2 \mathrm{~g})$ and it was cooled to $0{ }^{\circ} \mathrm{C}$ under argon. To the cold reaction mixture were added NIS (945 $\mathrm{mg}, 4.19 \mathrm{mmol}$ ) and $\mathrm{HClO}_{4}-\mathrm{SiO}_{2}(40 \mathrm{mg})$ and it was allowed to stir at same temperature for $15 \mathrm{~min}$. The reaction mixture was filtered and washed with $\mathrm{CH}_{2} \mathrm{Cl}_{2}(100 \mathrm{~mL})$. The combined filtrate was successively washed with $5 \% \mathrm{Na}_{2} \mathrm{~S}_{2} \mathrm{O}_{3}(50 \mathrm{~mL})$, satd aq. $\mathrm{NaHCO}_{3}$ $(50 \mathrm{~mL})$ and water $(50 \mathrm{~mL})$, dried $\left(\mathrm{Na}_{2} \mathrm{SO}_{4}\right)$ and concentrated under reduced pressure. The crude product was purified over $\mathrm{SiO}_{2}$ using hexane-EtOAc $(2: 1)$ as eluant to furnish pure compound 7 (1.9 g, 70\%). Colorless oil; $[\alpha]_{\mathrm{D}}^{25}-50\left(c 1.0, \mathrm{CHCl}_{3}\right)$; ${ }^{1} \mathrm{H}$ NMR (500 MHz, $\mathrm{CDCl}_{3}$ ): $\delta$ 7.68-6.94 (m, 15H, Ar-H), $5.56(\mathrm{~s}$, $1 \mathrm{H}, \mathrm{PhCH}$ ), 5.34 (d, $J=8.5 \mathrm{~Hz}, 1 \mathrm{H}, \mathrm{H}-1_{\mathrm{A}}$ ), 4.97 (dd, $J=10.5$, $\left.3.0 \mathrm{~Hz}, 1 \mathrm{H}, \mathrm{H}-3_{\mathrm{B}}\right), 4.84\left(\mathrm{~d}, J=3.5 \mathrm{~Hz}, 1 \mathrm{H}, \mathrm{H}-1_{\mathrm{B}}\right), 4.72(\mathrm{t}, J=$ $\left.9.0 \mathrm{~Hz}, 1 \mathrm{H}, \mathrm{H}-3_{\mathrm{A}}\right), 4.46-4.40\left(\mathrm{~m}, 4 \mathrm{H}, 2 \mathrm{PhCH}, \mathrm{H}-2_{\mathrm{A}}, \mathrm{H}-6_{\mathrm{aA}}\right), 4.14-$ $4.11\left(\mathrm{~m}, 2 \mathrm{H}, \mathrm{PhCH}, \mathrm{H}-5_{\mathrm{B}}\right), 4.01(\mathrm{~m}, 1 \mathrm{H}, \mathrm{OCH}), 3.97(\mathrm{~d}, J=$ $11.5 \mathrm{~Hz}, 1 \mathrm{H}, \mathrm{PhCH}), 3.87\left(\mathrm{t}, J=10.0 \mathrm{~Hz}, 1 \mathrm{H}, \mathrm{H}-6_{\mathrm{bA}}\right), 3.76(\mathrm{t}, J=$ $\left.9.0 \mathrm{~Hz}, 1 \mathrm{H}, \mathrm{H}-4_{\mathrm{A}}\right), 3.74-3.70\left(\mathrm{~m}, 2 \mathrm{H}, \mathrm{H}-2_{\mathrm{C}}, \mathrm{H}-5_{\mathrm{A}}\right), 3.68-3.63(\mathrm{~m}$, $1 \mathrm{H}, \mathrm{OCH}), 3.61\left(\mathrm{~d}, J=2.0 \mathrm{~Hz}, 1 \mathrm{H}, \mathrm{H}-4_{\mathrm{B}}\right), 3.41-3.35(\mathrm{~m}, 1 \mathrm{H}$, $\mathrm{NCH}$ ), 3.23-3.19 (m, 1H, NCH), 1.64 (s, 3H, $\left.\mathrm{COCH}_{3}\right), 0.74-0.73$ $\left(\mathrm{m}, 3 \mathrm{H}, \mathrm{CCH}_{3}\right) ;{ }^{13} \mathrm{C}$ NMR $\left(125 \mathrm{MHz}, \mathrm{CDCl}_{3}\right): \delta 170.1\left(\mathrm{COCH}_{3}\right)$, 168.2, 167.4 (PhthCO), 138.7-123.5 (Ar-C), 101.8 (PhCH), 99.1 $\left(\mathrm{C}-1_{\mathrm{A}}\right), 98.7\left(\mathrm{C}-1_{\mathrm{B}}\right), 81.6\left(\mathrm{C}-4_{\mathrm{A}}\right), 78.6\left(\mathrm{C}-4_{\mathrm{B}}\right), 77.3(\mathrm{PhCH}), 75.6(\mathrm{C}-$ $\left.2_{\mathrm{B}}\right), 75.5\left(\mathrm{C}-3_{\mathrm{A}}\right), 74.7\left(\mathrm{C}-3_{\mathrm{B}}\right), 73.5(\mathrm{PhCH}), 68.7(\mathrm{OCH}), 68.5\left(\mathrm{C}-6_{\mathrm{A}}\right)$, $66.6\left(\mathrm{C}-5_{\mathrm{A}}\right), 66.5\left(\mathrm{C}-5_{\mathrm{B}}\right), 55.6\left(\mathrm{C}-2_{\mathrm{A}}\right), 50.5(\mathrm{NCH}), 21.1\left(\mathrm{COCH}_{3}\right)$, 16.3 $\left(\mathrm{CCH}_{3}\right)$; MALDI-MS: 857.3 $[\mathrm{M}+\mathrm{Na}]^{+}$; anal. calcd for $\mathrm{C}_{45} \mathrm{H}_{46} \mathrm{~N}_{4} \mathrm{O}_{12}$ (834.86): C, 64.74; H, 5.55\%; found: C, 64.60; H, $5.70 \%$.
2-Azidoethyl $O$-(2,4-di-O-benzyl- $\alpha$-L-fucopyranosyl)-(1 $\rightarrow 3)$-2-

$N$-phthalimido-4,6-O-benzylidene-2-deoxy- $\beta$-Dglucopyranoside (8)

A solution of compound $7(1.7 \mathrm{~g}, 2.04 \mathrm{mmol})$ in $0.1 \mathrm{M} \mathrm{CH}_{3} \mathrm{ONa}$ in $\mathrm{CH}_{3} \mathrm{OH}(20 \mathrm{~mL})$ was allowed to stir at room temperature for $3 \mathrm{~h}$. The reaction mixture was neutralized with Dowex 50W X8 $\left(\mathrm{H}^{+}\right)$resin, filtered and concentrated under reduced pressure. The crude mass was passed through a short pad of $\mathrm{SiO}_{2}$ using hexane-EtOAc $(1: 1)$ as eluant to give pure compound 8 (1.5 g, 93\%). White solid; mp $174-175{ }^{\circ} \mathrm{C}[\mathrm{EtOH}] ;[\alpha]_{\mathrm{D}}^{25}-97$ (c 1.0, $\left.\mathrm{CHCl}_{3}\right) ;{ }^{1} \mathrm{H}$ NMR $\left(500 \mathrm{MHz}, \mathrm{CDCl}_{3}\right): \delta$ 7.75-6.97 (m, 15H, Ar-H), $5.55(\mathrm{~s}, 1 \mathrm{H}, \mathrm{PhCH}), 5.36$ (d, $\left.J=3.0 \mathrm{~Hz}, \mathrm{H}-1_{\mathrm{B}}\right), 4.70(\mathrm{t}, J=9.0 \mathrm{~Hz}$, $\left.1 \mathrm{H}, \mathrm{H}-3_{\mathrm{A}}\right), 4.57$ (d, $\left.J=11.5 \mathrm{~Hz}, 1 \mathrm{H}, \mathrm{PhCH}\right), 4.49$ (d, $J=11.5 \mathrm{~Hz}$, $1 \mathrm{H}, \mathrm{PhCH}), 4.40\left(\mathrm{~m}, 1 \mathrm{H}, \mathrm{H}-6_{\mathrm{aA}}\right), 4.39$ (t, $\left.J=9.0 \mathrm{~Hz}, 1 \mathrm{H}, \mathrm{H}-2_{\mathrm{A}}\right)$, 4.30 (d, $J=12.5 \mathrm{~Hz}, 1 \mathrm{H}, \mathrm{PhCH}$ ), 4.12-4.09 (m, 1H, H-5 ${ }_{\mathrm{B}}$ ), 4.01$3.95\left(\mathrm{~m}, 1 \mathrm{H}, \mathrm{H}-6_{\mathrm{bA}}\right), 3.87$ (d, $\left.J=10.0 \mathrm{~Hz}, 1 \mathrm{H}, \mathrm{PhCH}\right), 3.85-3.79$ (m, $\left.2 \mathrm{H}, \mathrm{H}-3_{\mathrm{B}}, \mathrm{OCH}\right), 3.75-3.60$ (m, $\left.3 \mathrm{H}, \mathrm{H}-4_{\mathrm{A}}, \mathrm{H}-5_{\mathrm{A}}, \mathrm{OCH}\right), 3.45$ (d, $\left.J=3.0 \mathrm{~Hz}, 1 \mathrm{H}, \mathrm{H}-4_{\mathrm{B}}\right), 3.43\left(\mathrm{~s}, 1 \mathrm{H}, \mathrm{H}-2_{\mathrm{B}}\right), 3.73-3.33$ (m, 1H, NCH), 3.21-3.17 (m, 1H, NCH), 0.87-0.85 (m, 3H, CCH $\left.{ }_{3}\right)$; ${ }^{13} \mathrm{C}$ NMR (125 $\mathrm{MHz} \mathrm{CDCl}_{3}$ ): $\delta$ 168.2, 167.4 (PhthCO), 134.0-125.3 (Ar-C), 101.6 $(\mathrm{PhCH}), 99.0\left(\mathrm{C}-1_{\mathrm{A}}\right), 97.8\left(\mathrm{C}-1_{\mathrm{B}}\right), 81.6\left(\mathrm{C}-4_{\mathrm{A}}\right), 79.9\left(\mathrm{C}-4_{\mathrm{B}}\right), 78.6(\mathrm{C}-$ $\left.2_{\mathrm{B}}\right), 77.3(\mathrm{PhCH}), 76.2\left(\mathrm{C}-3_{\mathrm{A}}\right), 75.5(\mathrm{PhCH}), 70.1\left(\mathrm{C}-3_{\mathrm{B}}\right), 68.7$ $\left(\mathrm{OCH}_{2}\right), 68.6\left(\mathrm{C}-6_{\mathrm{A}}\right), 67.0\left(\mathrm{C}-5_{\mathrm{A}}\right), 66.4\left(\mathrm{C}-5_{\mathrm{B}}\right), 55.7\left(\mathrm{C}-2_{\mathrm{A}}\right), 50.5$ $\left(\mathrm{NCH}_{2}\right), 15.8\left(\mathrm{CCH}_{3}\right)$; MALDI-MS: $815.3[\mathrm{M}+\mathrm{Na}]^{+}$; anal. calcd for $\mathrm{C}_{43} \mathrm{H}_{44} \mathrm{~N}_{4} \mathrm{O}_{11}$ (792.83): C, 65.14; H, 5.59\%; found: C, 64.95; H, $5.75 \%$.

\section{2-Azidoethyl $O$-(6-O-allyl-2,3,4-tri-O-benzyl- $\alpha$-D-} galactopyranosyl)-(1 $\rightarrow 3)-(2,4-d i-O$-benzyl- $\alpha-\mathrm{L}-$ fucopyranosyl)$(1 \rightarrow 3)-2-N$-phthalimido-4,6-O-benzylidene-2-deoxy- $\beta$-Dglucopyranoside (9)

A solution of compound $8(1.4 \mathrm{~g}, 1.77 \mathrm{mmol})$, compound 4 $(1.1 \mathrm{~g}, 2.06 \mathrm{mmol})$ and MS $4 \AA$ 的 $\mathrm{g})$ in anhydrous $\mathrm{CH}_{2} \mathrm{Cl}_{2}-\mathrm{Et}_{2} \mathrm{O}$ $(15 \mathrm{~mL}, 1: 3 \mathrm{v} / \mathrm{v})$ was cooled to $-10{ }^{\circ} \mathrm{C}$ under argon. NIS (560 $\mathrm{mg}, 2.5 \mathrm{mmol})$ and $\mathrm{HClO}_{4}-\mathrm{SiO}_{2}(20 \mathrm{mg})$ were added to the cold reaction mixture and it was allowed to stir at same temperature for $25 \mathrm{~min}$. The reaction mixture was filtered and washed with $\mathrm{CH}_{2} \mathrm{Cl}_{2}(100 \mathrm{~mL})$. The combined filtrate was successively washed with $5 \% \mathrm{Na}_{2} \mathrm{~S}_{2} \mathrm{O}_{3}(50 \mathrm{~mL})$, satd aq. $\mathrm{NaHCO}_{3}$ $(50 \mathrm{~mL})$ and water $(50 \mathrm{~mL})$, dried $\left(\mathrm{Na}_{2} \mathrm{SO}_{4}\right)$ and concentrated under reduced pressure. The crude product was purified over $\mathrm{SiO}_{2}$ using hexane-EtOAc $(3: 1)$ as eluant to furnish pure compound $9(1.7 \mathrm{~g}, 76 \%)$. Colorless oil; $[\alpha]_{\mathrm{D}}^{25}+30\left(c 1.0, \mathrm{CHCl}_{3}\right)$; ${ }^{1} \mathrm{H}$ NMR (500 MHz, $\mathrm{CDCl}_{3}$ ): $\delta$ 7.70-6.84 (m, 30H, Ar- $H$ ), 5.90$5.80\left(\mathrm{~m}, 1 \mathrm{H}, \mathrm{OC} H=\mathrm{CH}_{2}\right), 5.53(\mathrm{~s}, 1 \mathrm{H}, \mathrm{PhCH}), 5.33(\mathrm{~d}, J=8.5 \mathrm{~Hz}$, $\left.1 \mathrm{H}, \mathrm{H}-1_{\mathrm{A}}\right), 5.28-5.15\left(\mathrm{~m}, 2 \mathrm{H}, \mathrm{CH}=\mathrm{CH}_{2}\right), 4.92(\mathrm{~d}, J=11.5 \mathrm{~Hz}, 1 \mathrm{H}$, $\mathrm{PhCH}), 4.85$ (d, $\left.J=3.5 \mathrm{~Hz}, 1 \mathrm{H}, \mathrm{H}-1_{\mathrm{B}}\right), 4.72$ (d, $J=11.5 \mathrm{~Hz}, 1 \mathrm{H}$, $\mathrm{PhCH}), 4.65$ (d, $\left.J=3.0 \mathrm{~Hz}, 1 \mathrm{H}, \mathrm{H}-1_{\mathrm{C}}\right), 4.63-4.59\left(\mathrm{~m}, 2 \mathrm{H}, \mathrm{H}-3_{\mathrm{A}}\right.$, $\left.\mathrm{OCH}_{2}-\mathrm{CH}=\right)$, 4.56-4.51 (m, 5H, 5PhCH), 4.41-4.37 (m, 2H, H$\left.6_{\mathrm{aA}}, \mathrm{OCH}_{2}-\mathrm{CH}=\right), 4.35\left(\mathrm{t}, J=10.5 \mathrm{~Hz}, 1 \mathrm{H}, \mathrm{H}-2_{\mathrm{A}}\right), 4.27(\mathrm{~d}, J=$ $12.5 \mathrm{~Hz}, 1 \mathrm{H}, \mathrm{PhCH}), 4.08-4.03\left(\mathrm{~m}, 1 \mathrm{H}, \mathrm{H}-5_{\mathrm{B}}\right), 4.02-3.92(\mathrm{~m}, 3 \mathrm{H}$, $\left.\mathrm{PhCH}, \mathrm{H}-3_{\mathrm{B}}, \mathrm{H}-6_{\mathrm{bA}}\right), 3.91-3.80$ (m, 2H, H-2, OCH), 3.78-3.60 (m, $\left.7 \mathrm{H}, \mathrm{H}-2_{\mathrm{C}}, \mathrm{H}-3_{\mathrm{C}}, \mathrm{H}-4_{\mathrm{A}}, \mathrm{H}-4_{\mathrm{C}}, \mathrm{H}-5_{\mathrm{A}}, \mathrm{H}-5_{\mathrm{C}}, \mathrm{OCH}\right), 3.59-3.51(\mathrm{~m}, 1 \mathrm{H}$, $\left.\mathrm{H}-6_{\mathrm{aC}}\right), 3.50\left(\mathrm{~s}, 1 \mathrm{H}, \mathrm{H}-4_{\mathrm{B}}\right), 3.49-3.41\left(\mathrm{~m}, 1 \mathrm{H}, \mathrm{H}-6_{\mathrm{bC}}\right), 3.38-3.31$ $(\mathrm{m}, 1 \mathrm{H}, \mathrm{NCH}), 0.85-0.84\left(\mathrm{~m}, 3 \mathrm{H}, \mathrm{CCH}_{3}\right) ;{ }^{13} \mathrm{C} \mathrm{NMR}(125 \mathrm{MHz}$, $\mathrm{CDCl}_{3}$ ): $\delta$ 167.8, 168.4 (PhthCO), 138.9-125.5 (Ar-C, $\mathrm{CH}_{2}=\mathrm{CH}$ ), 
$117.0\left(\mathrm{CH}_{2}=\mathrm{CH}\right), 101.4(\mathrm{PhCH}), 99.5\left(\mathrm{C}-1_{\mathrm{C}}\right), 99.0\left(\mathrm{C}-1_{\mathrm{A}}\right), 98.4(\mathrm{C}-$ $\left.1_{\mathrm{B}}\right), 81.9\left(\mathrm{C}-4_{\mathrm{A}}\right), 81.6\left(\mathrm{C}-4_{\mathrm{B}}\right), 78.6\left(\mathrm{C}-4_{\mathrm{C}}\right), 75.8\left(\mathrm{C}-2_{\mathrm{B}}\right), 75.5(\mathrm{PhCH})$, $74.9\left(3 \mathrm{C}, \mathrm{C}-2_{\mathrm{C}}, \mathrm{C}-3_{\mathrm{C}}, \mathrm{C}-5_{\mathrm{C}}\right), 73.1\left(\mathrm{C}-3_{\mathrm{A}}\right), 72.9(\mathrm{PhCH}), 72.7$ $(\mathrm{PhCH}), 72.4(\mathrm{PhCH}), 72.3\left(\mathrm{OCH}_{2}-\mathrm{CH}=\mathrm{CH}_{2}\right), 70.4\left(\mathrm{C}-3_{\mathrm{B}}\right), 69.4$ $\left(\mathrm{C}-6_{\mathrm{C}}\right), 68.7\left(\mathrm{OCH}_{2}\right), 68.5\left(\mathrm{C}-6_{\mathrm{A}}\right), 68.1\left(\mathrm{C}-5_{\mathrm{A}}\right), 67.5\left(\mathrm{C}-5_{\mathrm{B}}\right), 55.6(\mathrm{C}-$ $\left.2_{\mathrm{A}}\right), 50.5\left(\mathrm{NCH}_{2}\right), 16.3\left(\mathrm{CCH}_{3}\right)$; MALDI-MS: $1287.5[\mathrm{M}+\mathrm{Na}]^{+}$; anal. calcd for $\mathrm{C}_{73} \mathrm{H}_{76} \mathrm{~N}_{4} \mathrm{O}_{16}$ (1265.40): C, 69.29; $\mathrm{H}, 6.05 \%$; found: C, 69.10; H, 6.20\%.

2-Azidoethyl $O$-(2,3,4-tri- $O$-benzyl- $\alpha$-D-galactopyranosyl)-(1 $\rightarrow$ 3)-(2,4-di-O-benzyl- $\alpha$-L-fucopyranosyl)-(1 $\rightarrow 3)-4,6$-di- $O$-acetyl2- $N$-phthalimido-2-deoxy- $\beta$-D-glucopyranoside (11)

To a solution of compound $9(1.7 \mathrm{~g}, 1.34 \mathrm{mmol})$ in acetic anhydride $(5 \mathrm{~mL})$ was added $\mathrm{HClO}_{4}-\mathrm{SiO}_{2}(200 \mathrm{mg})$ and the reaction mixture was stirred at room temperature for $20 \mathrm{~min}$. The reaction mixture was filtered and washed with EtOAc (50 $\mathrm{mL}$ ). The combined filtrate was concentrated and co-evaporated with toluene $(3 \times 20 \mathrm{~mL})$ under reduced pressure. The crude product was passed through a short pad of $\mathrm{SiO}_{2}$ using hexaneEtOAc (2:1) as eluant to give pure compound 10 (1.49 g, 88\%). To a solution of compound $10(1.4 \mathrm{~g}, 1.11 \mathrm{mmol})$ in dry $\mathrm{CH}_{3} \mathrm{OH}$ $(25 \mathrm{~mL})$ was added $\mathrm{PdCl}_{2}(100 \mathrm{mg}, 0.56 \mathrm{mmol})$ and the reaction mixture was stirred at $0{ }^{\circ} \mathrm{C}$ for $1 \mathrm{~h}$. Then the reaction mixture was filtered through a Celite bed and washed with $\mathrm{CH}_{3} \mathrm{OH}(50$ $\mathrm{mL}$ ). The combined filtrate was concentrated under reduced pressure and the crude product was purified over $\mathrm{SiO}_{2}$ using hexane-EtOAc $(1: 1)$ as eluant to give pure compound 11 (980 mg, 72\%). Yellowish solid; mp 154-155 ${ }^{\circ} \mathrm{C}[\mathrm{EtOH}]$; $[\alpha]_{\mathrm{D}}^{25}+100\left(\right.$ c 1.0, $\left.\mathrm{CHCl}_{3}\right) ;{ }^{1} \mathrm{H}$ NMR $\left(500 \mathrm{MHz}, \mathrm{CDCl}_{3}\right): \delta$ 7.71-6.95 $(\mathrm{m}, 25 \mathrm{H}, \operatorname{Ar}-H), 5.44\left(\mathrm{~d}, J=8.0 \mathrm{~Hz}, 1 \mathrm{H}, \mathrm{H}-1_{\mathrm{A}}\right), 5.03(\mathrm{~d}, J=$ $\left.10.0 \mathrm{~Hz}, 1 \mathrm{H}, \mathrm{H}-4_{\mathrm{A}}\right), 4.99$ (d, $\left.J=11.5 \mathrm{~Hz}, 1 \mathrm{H}, \mathrm{PhCH}\right), 4.75(\mathrm{~d}, J=$ 11.5 Hz, 1H, PhCH), 4.73 (d, $J=11.5 \mathrm{~Hz}, 1 \mathrm{H}, \mathrm{PhCH}), 4.63$ (d, $J=$ $11.5 \mathrm{~Hz}, 1 \mathrm{H}, \mathrm{PhCH}), 4.60$ (d, $J=11.5 \mathrm{~Hz}, 1 \mathrm{H}, \mathrm{PhCH}), 4.53$ (d, $J=$ 12.0 Hz, 1H, PhCH), 4.50 (d, $\left.J=3.0 \mathrm{~Hz}, 1 \mathrm{H}, \mathrm{H}-1_{\mathrm{B}}\right), 4.42$ (d, $J=$ 12.0 Hz, 1H, PhCH), 4.40 (d, $J=11.5 \mathrm{~Hz}, 1 \mathrm{H}, \mathrm{PhCH}), 4.30$ (d, $J=$ $\left.3.0 \mathrm{~Hz}, 1 \mathrm{H}, \mathrm{H}-1_{\mathrm{C}}\right), 4.28-4.25\left(\mathrm{~m}, 2 \mathrm{H}, \mathrm{H}-2_{\mathrm{A}}, \mathrm{H}-4_{\mathrm{C}}\right), 4.20-4.01$ (m, $\left.6 \mathrm{H}, 2 \mathrm{PhCH}, \mathrm{H}-3_{\mathrm{A}}, \mathrm{H}-6_{\mathrm{abA}}, \mathrm{OCH}\right), 3.98-3.90$ (m, 1H, H-5 ${ }_{\mathrm{B}}$ ), 3.85$3.78\left(\mathrm{~m}, 2 \mathrm{H}, \mathrm{H}-2_{\mathrm{B}}, \mathrm{H}-3_{\mathrm{C}}\right), 3.71-3.69\left(\mathrm{~m}, 3 \mathrm{H}, \mathrm{H}-5_{\mathrm{A}}, \mathrm{H}-5_{\mathrm{C}}, \mathrm{OCH}\right)$, $3.68-3.58\left(\mathrm{~m}, 2 \mathrm{H}, \mathrm{H}-2_{\mathrm{C}}, \mathrm{H}-3_{\mathrm{B}}\right), 3.55-3.39$ (m, 4H, H-4 $4_{\mathrm{B}}, \mathrm{H}-6_{\mathrm{abC}}$, $\mathrm{NCH}$ ), 3.20-3.15 (m, 1H, NCH), 2.1, 1.9 (s, 6H, 2COCH $), 1.01-$ $1.00\left(\mathrm{~m}, 3 \mathrm{H}, \mathrm{CCH}_{3}\right) ;{ }^{13} \mathrm{C} \mathrm{NMR}\left(125 \mathrm{MHz} \mathrm{CDCl}_{3}\right): \delta 170.8,169.7$ $\left(\mathrm{COCH}_{3}\right), 168.2$, 167.4 (PhthCO), 138.6-122.3 (Ar-C), 101.3 (C$\left.1_{\mathrm{C}}\right), 98.6\left(\mathrm{C}-1_{\mathrm{A}}\right), 95.9\left(\mathrm{C}-1_{\mathrm{B}}\right), 80.9\left(\mathrm{C}-4_{\mathrm{B}}\right), 78.7\left(\mathrm{C}-4_{\mathrm{C}}\right), 78.4\left(\mathrm{C}-2_{\mathrm{B}}\right)$, $76.4\left(\mathrm{C}-2_{\mathrm{C}}\right), 76.3\left(\mathrm{C}-3_{\mathrm{C}}\right), 75.8(\mathrm{PhCH}), 75.5\left(\mathrm{C}-5_{\mathrm{C}}\right), 74.3(\mathrm{PhCH})$, $73.6(\mathrm{PhCH}), 72.9(\mathrm{PhCH}), 72.7(\mathrm{PhCH}), 72.5\left(\mathrm{C}-3_{\mathrm{A}}\right), 72.1\left(\mathrm{C}-3_{\mathrm{B}}\right)$, $71.2\left(\mathrm{C}-5_{\mathrm{A}}\right), 71.1\left(\mathrm{C}-4_{\mathrm{A}}\right), 68.6\left(\mathrm{OCH}_{2}\right), 68.4\left(\mathrm{C}-5_{\mathrm{B}}\right), 54.8\left(\mathrm{C}-2_{\mathrm{A}}\right), 50.4$ $\left(\mathrm{NCH}_{2}\right), 21.2,20.9\left(2 \mathrm{COCH}_{3}\right), 15.7\left(\mathrm{CCH}_{3}\right)$; MALDI-MS: 1243.4 $[\mathrm{M}+\mathrm{Na}]^{+}$; anal. calcd for $\mathrm{C}_{67} \mathrm{H}_{72} \mathrm{~N}_{4} \mathrm{O}_{18}$ (1221.30): C, 65.89; $\mathrm{H}$, $5.94 \%$; found: C, 65.74; $\mathrm{H}, 6.06 \%$.

\section{Ethyl (2,3-di- $O$-benzyl-4,6-O-benzylidene- $\alpha$-D-} galactopyranosyl)-(1 $\rightarrow 3)$-4- $O$-acetyl-2-O-benzyl-1-thio- $\beta$-Lfucopyranoside (12)

To a solution of compound 5 (500 $\mathrm{mg}, 1.47 \mathrm{mmol}$ ) and compound $6(1.1 \mathrm{~g}, 1.86 \mathrm{mmol})$ in anhydrous $\mathrm{CH}_{2} \mathrm{Cl}_{2}-\mathrm{Et}_{2} \mathrm{O}(10$ $\mathrm{mL}, 1: 3 \mathrm{v} / \mathrm{v})$ was added MS $4 \AA$ ( $4 \mathrm{~g})$ and the reaction mixture was allowed to stir at room temperature for 10 min under argon then cooled to $-10{ }^{\circ} \mathrm{C}$. To the cooled reaction mixture was added $\mathrm{HClO}_{4}-\mathrm{SiO}_{2}(50 \mathrm{mg})$ and it was allowed to stir at the same temperature for $2 \mathrm{~h}$. The reaction was quenched with $\mathrm{Et}_{3} \mathrm{~N}(0.1$ $\mathrm{mL})$, filtered and washed with $\mathrm{CH}_{2} \mathrm{Cl}_{2}(100 \mathrm{~mL})$. The organic layer was washed with satd aq. $\mathrm{NaHCO}_{3}(50 \mathrm{~mL})$ and water (50 $\mathrm{mL})$, dried $\left(\mathrm{Na}_{2} \mathrm{SO}_{4}\right)$ and concentrated. The crude product was purified over $\mathrm{SiO}_{2}$ using hexane-EtOAc (2:1) as eluant to give pure compound 12 (840 mg, 74\%). White solid; $109-110{ }^{\circ} \mathrm{C}$ $[\mathrm{EtOH}] ;[\alpha]_{\mathrm{D}}^{25}+44.3\left(\right.$ c $\left.1.0, \mathrm{CHCl}_{3}\right) ;{ }^{1} \mathrm{H}$ NMR (500 $\mathrm{MHz}, \mathrm{CDCl}_{3}$ ): $\delta$ 7.55-7.12 (m, 20H, Ar-H), $5.52(\mathrm{~s}, 1 \mathrm{H}, \mathrm{PhCH}), 5.44(\mathrm{~d}, J=$ $\left.3.5 \mathrm{~Hz}, 1 \mathrm{H}, \mathrm{H}-1_{\mathrm{E}}\right), 5.12$ (d, $\left.J=3.5 \mathrm{~Hz}, 1 \mathrm{H}, \mathrm{H}-4_{\mathrm{D}}\right), 4.90$ (d, $J=$ $12.0 \mathrm{~Hz}, 1 \mathrm{H}, \mathrm{PhCH}), 4.83-4.71(4 \mathrm{~d}, J=12 \mathrm{~Hz}, 4 \mathrm{H}, 4 \mathrm{PhCH}), 4.57$ $(\mathrm{d}, 1 \mathrm{H}, J=12.5 \mathrm{~Hz}, \mathrm{PhCH}), 4.44$ (d, $\left.J=9.5 \mathrm{~Hz}, 1 \mathrm{H}, \mathrm{H}-1_{\mathrm{D}}\right), 4.27$ (d, $\left.J=2.5 \mathrm{~Hz}, 1 \mathrm{H}, \mathrm{H}-4_{\mathrm{E}}\right), 4.25$ (d, $\left.J=12.5 \mathrm{~Hz}, 1 \mathrm{H}, \mathrm{H}-6_{\mathrm{aE}}\right), 4.12$ (dd, $J$ $\left.=9.0,3.0 \mathrm{~Hz}, 1 \mathrm{H}, \mathrm{H}-2_{\mathrm{E}}\right), 4.09\left(\mathrm{~d}, J=11.5 \mathrm{~Hz}, \mathrm{H}-6_{\mathrm{bE}}\right), 3.98-3.91$ (m, 2H, H-3 $\left.{ }_{\mathrm{D}}, \mathrm{H}-3_{\mathrm{E}}\right), 3.86$ (s, $\left.1 \mathrm{H}, \mathrm{H}-5_{\mathrm{E}}\right), 3.78-3.73\left(\mathrm{~m}, 1 \mathrm{H}, \mathrm{H}-5_{\mathrm{D}}\right)$, $3.71\left(\mathrm{t}, J=8.5 \mathrm{~Hz}, 1 \mathrm{H}\right.$ each, $\left.\mathrm{H}-2_{\mathrm{D}}\right), 2.85-2.70\left(\mathrm{~m}, 2 \mathrm{H}, \mathrm{SCH}_{2} \mathrm{CH}_{3}\right)$, $2.06\left(\mathrm{~s}, 3 \mathrm{H}, \mathrm{COCH}_{3}\right), 1.35\left(\mathrm{t}, J=7.5 \mathrm{~Hz}, 3 \mathrm{H}, \mathrm{SCH}_{2} \mathrm{CH}_{3}\right), 1.19-1.74$ $\left(\mathrm{m}, 3 \mathrm{H}, \mathrm{CCH}_{3}\right) ;{ }^{13} \mathrm{C}$ NMR $\left(125 \mathrm{MHz}, \mathrm{CDCl}_{3}\right): \delta 171.3\left(\mathrm{COCH}_{3}\right)$, 138.6-126.4 (Ar-C), 100.9 (PhCH), 100.0 (C-1 $)$ $), 85.2\left(\mathrm{C}-1_{\mathrm{D}}\right), 78.3$ $\left(\mathrm{C}-2_{\mathrm{D}}\right), 77.6\left(\mathrm{C}-3_{\mathrm{D}}\right), 75.6\left(\mathrm{C}-3_{\mathrm{E}}\right), 75.1(\mathrm{PhCH}), 74.8\left(\mathrm{C}-2_{\mathrm{E}}\right), 74.5(\mathrm{C}-$ 4 $) 73.8(\mathrm{PhCH}), 73.0\left(\mathrm{C}-5_{\mathrm{D}}\right), 72.9\left(\mathrm{C}-4_{\mathrm{D}}\right), 71.4(\mathrm{PhCH}), 69.6$ $(\mathrm{PhCH}), 68.9\left(\mathrm{C}-6_{\mathrm{E}}\right), 63.4\left(\mathrm{C}-5_{\mathrm{E}}\right), 25.6\left(\mathrm{SCH}_{2} \mathrm{CH}_{3}\right), 22.7\left(\mathrm{COCH}_{3}\right)$, 16.6 $\left(\mathrm{CCH}_{3}\right), 16.1\left(\mathrm{SCH}_{2} \mathrm{CH}_{3}\right)$; MALDI-MS: $793.3[\mathrm{M}+\mathrm{Na}]^{+}$; anal. calcd for $\mathrm{C}_{44} \mathrm{H}_{50} \mathrm{O}_{10} \mathrm{~S}$ (770.92): C, 68.55; $\mathrm{H}, 6.54 \%$; found: $\mathrm{C}$, $68.40 ; \mathrm{H}, 6.70 \%$.

\section{2-Azidoethyl $O$-(2,3-di-O-benzyl-4,6-O-benzylidene- $\alpha$-D- galactopyranosyl)-(1 $\rightarrow 3)$-(4-O-acetyl-2-O-benzyl- $\alpha$-L- fucopyranosyl)-(1 $\rightarrow$ 6)-(2,3,4-tri-O-benzyl- $\alpha$-D- galactopyranosyl)-(1 $\rightarrow$ 3)-(2,4-di-O-benzyl- $\alpha$-L-fucopyranosyl)- $(1 \rightarrow 3)-4,6$-di-O-acetyl-2- $N$-phthalimido-2-deoxy- $\beta$-D- glucopyranoside (13)}

A solution of compound 11 (900 $\mathrm{mg}, 0.72 \mathrm{mmol}$ ), compound 12 (660 mg, $0.86 \mathrm{mmol}$ ) and MS $4 \AA$ ( $1 \mathrm{~g})$ in anhydrous $\mathrm{CH}_{2} \mathrm{Cl}_{2}-$ $\mathrm{Et}_{2} \mathrm{O}(15 \mathrm{~mL}, 1: 4 \mathrm{v} / \mathrm{v})$ was cooled to $-10^{\circ} \mathrm{C}$ under argon. NIS $(230 \mathrm{mg}, 1.03 \mathrm{mmol})$ and $\mathrm{HClO}_{4}-\mathrm{SiO}_{2}(10 \mathrm{mg})$ were added to the cold reaction mixture and it was allowed to stir at same temperature for $30 \mathrm{~min}$. The reaction mixture was filtered and washed with $\mathrm{CH}_{2} \mathrm{Cl}_{2}(50 \mathrm{~mL})$. The combined filtrate was successively washed with $5 \% \mathrm{Na}_{2} \mathrm{~S}_{2} \mathrm{O}_{3}(25 \mathrm{~mL})$, satd aq. $\mathrm{NaHCO}_{3}$ $(25 \mathrm{~mL})$ and water $(25 \mathrm{~mL})$, dried $\left(\mathrm{Na}_{2} \mathrm{SO}_{4}\right)$ and concentrated under reduced pressure. The crude product was purified over $\mathrm{SiO}_{2}$ using hexane-EtOAc $(3: 2)$ as eluant to give pure compound 13 (1.0 g, 72\%). White solid; mp 167-168 ${ }^{\circ} \mathrm{C}$ [EtOH]; $[\alpha]_{\mathrm{D}}^{25}+46\left(c\right.$ 1.0, $\left.\mathrm{CHCl}_{3}\right) ;{ }^{1} \mathrm{H} \mathrm{NMR}\left(500 \mathrm{MHz}, \mathrm{CDCl}_{3}\right): \delta 7.92-6.87$ $(\mathrm{m}, 45 \mathrm{H}, \operatorname{Ar}-H), 5.57$ (d, J=3.5 Hz, 1H, H-1 $\left.{ }_{\mathrm{D}}\right), 5.50(\mathrm{~s}, 1 \mathrm{H}, \mathrm{PhCH})$, $5.42\left(\mathrm{~d}, J=7.5 \mathrm{~Hz}, 1 \mathrm{H}, \mathrm{H}-1_{\mathrm{A}}\right), 5.12(\mathrm{~d}, J=12.0 \mathrm{~Hz}, 1 \mathrm{H}, \mathrm{PhCH})$, $5.02\left(\mathrm{~d}, J=3.0 \mathrm{~Hz}, 1 \mathrm{H}, \mathrm{H}-4_{\mathrm{D}}\right), 4.95\left(\mathrm{t}, J=9.0 \mathrm{~Hz}\right.$ each, $\left.1 \mathrm{H}, \mathrm{H}-4_{\mathrm{A}}\right)$, $4.86\left(\mathrm{~d}, J=3.0 \mathrm{~Hz}, 1 \mathrm{H}, \mathrm{H}-1_{\mathrm{E}}\right), 4.65\left(\mathrm{~d}, J=3.0 \mathrm{~Hz}, 1 \mathrm{H}, \mathrm{H}-1_{\mathrm{B}}\right), 4.74-$ $4.42\left(\mathrm{~m}, 11 \mathrm{H}, 9 \mathrm{PhCH}, \mathrm{H}-6_{\mathrm{abA}}\right), 4.38-4.03\left(\mathrm{~m}, 13 \mathrm{H}, \mathrm{H}-2_{\mathrm{A}}, \mathrm{H}-2_{\mathrm{D}}\right.$, $\left.\mathrm{H}-3_{\mathrm{A}}, \mathrm{H}-3_{\mathrm{D}}, \mathrm{H}-4_{\mathrm{E}}, \mathrm{H}-6_{\mathrm{aE}}, \mathrm{H}-6_{\mathrm{bE}}, 6 \mathrm{PhCH}\right), 4.23(\mathrm{~d}, J=3.0 \mathrm{~Hz}, 1 \mathrm{H}$, $\left.\mathrm{H}-1_{\mathrm{C}}\right), 4.09-3.98(\mathrm{~m}, 1 \mathrm{H}, \mathrm{OCH}), 3.95-3.78\left(\mathrm{~m}, 10 \mathrm{H}, \mathrm{H}-2_{\mathrm{B}}, \mathrm{H}-2_{\mathrm{E}}\right.$, $\left.\mathrm{H}-3_{\mathrm{B}}, \mathrm{H}-3_{\mathrm{C}}, \mathrm{H}-3_{\mathrm{E}}, \mathrm{H}-4_{\mathrm{C}}, \mathrm{H}-5_{\mathrm{B}}, \mathrm{H}-5_{\mathrm{C}}, \mathrm{H}-5_{\mathrm{D}}, \mathrm{H}-6_{\mathrm{aC}}\right), 3.79-3.63$ (m, $\left.2 \mathrm{H}, \mathrm{H}-5_{\mathrm{A}}, \mathrm{OCH}\right), 3.58-3.50\left(\mathrm{~m}, 2 \mathrm{H}, \mathrm{H}-2_{\mathrm{C}}, \mathrm{H}-6_{\mathrm{bC}}\right), 3.41-3.33$ (m, 
$\left.2 \mathrm{H}, \mathrm{H}-4_{\mathrm{B}}, \mathrm{NCH}\right), 3.25-3.15$ (m, 2H, H-5 $\left.\mathrm{E}, \mathrm{NCH}\right), 2.08,2.02,1.90$ $\left(3 \mathrm{~s}, 9 \mathrm{H}, 3 \mathrm{COCH}_{3}\right), 0.92-0.98\left(\mathrm{~m}, 6 \mathrm{H}, 2 \mathrm{CCH}_{3}\right) ;{ }^{13} \mathrm{C}$ NMR $(125$ $\left.\mathrm{MHz}, \mathrm{CDCl}_{3}\right): \delta 171.3,170.8,169.8\left(3 \mathrm{COCH}_{3}\right), 168.2,167.4$ (PhthCO), 139.2-122.7 (Ar-C), 102.4 (C-1 $\mathrm{C}), 101.1(\mathrm{PhCH}), 99.03$ $\left(\mathrm{C}-1_{\mathrm{D}}\right), 98.3\left(\mathrm{C}-1_{\mathrm{E}}\right), 98.2\left(\mathrm{C}-1_{\mathrm{B}}\right), 97.5\left(\mathrm{C}-1_{\mathrm{A}}\right), 81.9\left(\mathrm{C}-4_{\mathrm{B}}\right), 79.4(\mathrm{C}-$ $\left.4_{\mathrm{C}}\right), 79.0\left(\mathrm{C}-2_{\mathrm{B}}\right), 76.3\left(2 \mathrm{C}, \mathrm{C}-2_{\mathrm{C}}, \mathrm{C}-2_{\mathrm{D}}\right), 75.9(\mathrm{PhCH}), 75.3\left(\mathrm{C}-3_{\mathrm{C}}\right)$, $75.1\left(\mathrm{C}-5_{\mathrm{C}}\right), 74.9\left(\mathrm{C}-4_{\mathrm{E}}\right), 74.7\left(\mathrm{C}-3_{\mathrm{D}}\right), 74.5\left(2 \mathrm{C}, \mathrm{C}-2_{\mathrm{E}}, \mathrm{C}-3_{\mathrm{E}}\right), 73.3(\mathrm{C}-$ $\left.3_{\mathrm{B}}\right), 72.8(\mathrm{PhCH}), 72.7(\mathrm{PhCH}), 72.5(\mathrm{PhCH}), 72.1\left(\mathrm{C}-3_{\mathrm{A}}\right), 71.9$ $(\mathrm{PhCH}), 71.8\left(\mathrm{C}-4_{\mathrm{D}}\right), 71.4(\mathrm{PhCH}), 71.1\left(\mathrm{C}-5_{\mathrm{D}}\right), 69.6\left(\mathrm{C}-6_{\mathrm{E}}\right), 69.3$ $\left(\mathrm{C}-4_{\mathrm{A}}\right), 68.6\left(\mathrm{OCH}_{2}\right), 68.3\left(\mathrm{C}-5_{\mathrm{A}}\right), 66.2\left(\mathrm{C}-6_{\mathrm{C}}\right), 64.9\left(\mathrm{C}-5_{\mathrm{E}}\right), 63.3(\mathrm{C}-$ $\left.5_{\mathrm{B}}\right), 62.3\left(\mathrm{C}-6_{\mathrm{A}}\right), 54.8\left(\mathrm{C}-2_{\mathrm{A}}\right), 50.4\left(\mathrm{NCH}_{2}\right), 21.3,20.9(2 \mathrm{C})$ $\left(3 \mathrm{COCH}_{3}\right), 15.9,15.8\left(2 \mathrm{CCH}_{3}\right)$; MALDI-MS: $1951.8[\mathrm{M}+\mathrm{Na}]^{+}$; anal. calcd for $\mathrm{C}_{109} \mathrm{H}_{116} \mathrm{~N}_{4} \mathrm{O}_{28}$ (1930.09): C, 67.83; H, 6.06\%; found: C, $67.70 ; \mathrm{H}, 6.20 \%$.

\section{2-Azidoethyl $O$-(2,3-di-O-benzyl-4,6-O-[(R)-(1-carboxymethyl) ethylidene]- $\alpha$-D-galactopyranosyl)-(1 $\rightarrow 3)-(4-O$-acetyl-2-O- benzyl- $\alpha$-L-fucopyranosyl)-(1 $\rightarrow 6)-(2,3,4$-tri- $O$-benzyl- $\alpha$-D- galactopyranosyl)-(1 $\rightarrow 3)-(2,4-d i-O$-benzyl- $\alpha$-L-fucopyranosyl)- $(1 \rightarrow 3)-4,6$-di- $O$-acetyl-2- $N$-phthalimido-2-deoxy- $\beta$-D- glucopyranoside (15)}

To a solution of compound 13 (900 mg, $0.47 \mathrm{mmol}$ ) in $\mathrm{CH}_{3} \mathrm{CN}$ $(15 \mathrm{~mL})$ was added $\mathrm{HClO}_{4}-\mathrm{SiO}_{2}(100 \mathrm{mg})$ and it was stirred at room temperature for $20 \mathrm{~min}$. The reaction mixture was filtered and washed with EtOAc $(50 \mathrm{~mL})$. The solvents were removed under reduced pressure and the crude product was purified over $\mathrm{SiO}_{2}$ using hexane-EtOAc $(1: 1)$ as eluant to give pure compound 14 (705 mg, 82\%). To a solution of compound 14 $(500 \mathrm{mg}, 0.27 \mathrm{mmol})$ in dry $\mathrm{CH}_{3} \mathrm{CN}(15 \mathrm{~mL})$ was added methyl 2,2-di(ethylthio)propionate (170 $\mathrm{mg}, 0.81 \mathrm{mmol}$ ) and NIS (460 $\mathrm{mg}, 2.03 \mathrm{mmol}$ ) and the mixture was stirred at $0{ }^{\circ} \mathrm{C}$ under argon for $10 \mathrm{~min}$. To the cold reaction mixture was added $\mathrm{TfOH}$ $(15 \mu \mathrm{L})$ and it was stirred at $0{ }^{\circ} \mathrm{C}$ for a further $20 \mathrm{~min}$. After completion of the reaction (TLC), $10 \%$ aq. $\mathrm{Na}_{2} \mathrm{~S}_{2} \mathrm{O}_{3}(50 \mathrm{~mL})$ was added to the reaction mixture and the solvents were removed and the crude mass was diluted with $\mathrm{CH}_{2} \mathrm{Cl}_{2}(50 \mathrm{~mL})$. The organic solution was washed with satd aq. $\mathrm{NaHCO}_{3}(50 \mathrm{~mL})$ and water $(50 \mathrm{~mL})$, dried $\left(\mathrm{Na}_{2} \mathrm{SO}_{4}\right)$ and concentrated under reduced pressure. The crude product was purified over $\mathrm{SiO}_{2}$ using hexane-EtOAc $(3: 1)$ to give the pure compound $15(360 \mathrm{mg}$, 68\%). White solid; mp 144-145 ${ }^{\circ} \mathrm{C}[\mathrm{EtOH}] ;[\alpha]_{\mathrm{D}}^{25}+22.8$ (c 1.0, $\left.\mathrm{CHCl}_{3}\right) ;{ }^{1} \mathrm{H}$ NMR $\left(500 \mathrm{MHz}, \mathrm{CDCl}_{3}\right): \delta$ 7.92-6.93 (m, 40H, Ar-H), $5.55\left(\mathrm{~d}, J=3.5 \mathrm{~Hz}, 1 \mathrm{H}, \mathrm{H}-1_{\mathrm{D}}\right), 5.42\left(\mathrm{~d}, J=8.0 \mathrm{~Hz}, 1 \mathrm{H}, \mathrm{H}-1_{\mathrm{A}}\right), 5.15$ (d, $J=12.0 \mathrm{~Hz}, 1 \mathrm{H}, \mathrm{PhCH}), 5.13-4.95\left(\mathrm{~m}, 2 \mathrm{H}, \mathrm{H}-4_{\mathrm{A}}, \mathrm{H}-4_{\mathrm{D}}\right), 4.89$ (d, $\left.J=3.0 \mathrm{~Hz}, 1 \mathrm{H}, \mathrm{H}-1_{\mathrm{E}}\right), 4.87$ (d, $\left.J=12.0 \mathrm{~Hz}, 1 \mathrm{H}, \mathrm{PhCH}\right), 4.79-$ 4.45 (m, 9H, 9PhCH), 4.67 (d, $\left.J=3.5 \mathrm{~Hz}, 1 \mathrm{H}, \mathrm{H}-1_{\mathrm{B}}\right), 4.41-4.30$ $\left(\mathrm{m}, 7 \mathrm{H}, \mathrm{H}-2_{\mathrm{A}}, \mathrm{H}-3_{\mathrm{A}}, \mathrm{H}-4_{\mathrm{E}}, \mathrm{H}-6_{\mathrm{aE}}, 3 \mathrm{PhCH}\right), 4.28(\mathrm{~d}, J=3.5 \mathrm{~Hz}, 1 \mathrm{H}$, $\left.\mathrm{H}-1_{\mathrm{C}}\right), 4.25-4.13$ ( $\left.\mathrm{m}, 5 \mathrm{H}, \mathrm{H}-2_{\mathrm{D}}, \mathrm{H}-3_{\mathrm{D}}, \mathrm{H}-6_{\mathrm{bE}}, 2 \mathrm{PhCH}\right), 4.08-3.92$ (m, $\left.8 \mathrm{H}, \mathrm{H}-2_{\mathrm{B}}, \mathrm{H}-2_{\mathrm{E}}, \mathrm{H}-3_{\mathrm{B}}, \mathrm{H}-4_{\mathrm{C}}, \mathrm{H}-6_{\mathrm{abA}}, \mathrm{H}-6_{\mathrm{aC}}, \mathrm{OCH}\right), 3.90(\mathrm{~s}, 3 \mathrm{H}$, $\left.\mathrm{CO}_{2} \mathrm{CH}_{3}\right), 3.88-3.78\left(\mathrm{~m}, 5 \mathrm{H}, \mathrm{H}-3_{\mathrm{C}}, \mathrm{H}-3_{\mathrm{E}}, \mathrm{H}-5_{\mathrm{B}}, \mathrm{H}-5_{\mathrm{C}}, \mathrm{H}-5_{\mathrm{D}}\right), 3.76-$ $3.68\left(\mathrm{~m}, 2 \mathrm{H}, \mathrm{H}-5_{\mathrm{A}}, \mathrm{OCH}\right), 3.62-3.55\left(\mathrm{~m}, 2 \mathrm{H}, \mathrm{H}-2_{\mathrm{C}}, \mathrm{H}-6_{\mathrm{bC}}\right), 3.47-$ $3.38\left(\mathrm{~m}, 2 \mathrm{H}, \mathrm{NCH}, \mathrm{H}-4_{\mathrm{B}}\right), 3.28-3.19\left(\mathrm{~m}, 2 \mathrm{H}, \mathrm{NCH}, \mathrm{H}-5_{\mathrm{E}}\right), 2.08$, 2.00, $1.95\left(3 \mathrm{~s}, 9 \mathrm{H}, 3 \mathrm{COCH}_{3}\right), 1.61\left(\mathrm{~s}, 3 \mathrm{H}, \mathrm{CCH}_{3}\right), 0.97-0.89(\mathrm{~m}$, $6 \mathrm{H}, 2 \mathrm{CCH}_{3}$ ); ${ }^{13} \mathrm{C} \mathrm{NMR}\left(125 \mathrm{MHz}, \mathrm{CDCl}_{3}\right): \delta 171.3,170.8,170.7$ $\left(3 \mathrm{COCH}_{3}\right), 169.8\left(\mathrm{CO}_{2} \mathrm{CH}_{3}\right), 168.2,167.4$ (PhthCO), 139.2-122 $(\mathrm{Ar}-\mathrm{C}), 102.4\left(\mathrm{C}-1_{\mathrm{C}}\right), 99.08\left(\mathrm{C}-1_{\mathrm{D}}\right), 98.8\left(\mathrm{CCH}_{3}\right), 98.3\left(\mathrm{C}-1_{\mathrm{E}}\right), 98.1$
$\left(\mathrm{C}-1_{\mathrm{B}}\right), 97.5\left(\mathrm{C}-1_{\mathrm{A}}\right), 81.9\left(\mathrm{C}-4_{\mathrm{B}}\right), 79.4\left(\mathrm{C}-4_{\mathrm{C}}\right), 78.9\left(\mathrm{C}-2_{\mathrm{B}}\right), 76.3(2 \mathrm{C}$, $\left.\mathrm{C}-2_{\mathrm{C}}, \mathrm{C}-2_{\mathrm{D}}\right), 75.9(\mathrm{PhCH}), 75.3\left(2 \mathrm{C}, \mathrm{C}-3_{\mathrm{C}}, \mathrm{C}-5_{\mathrm{C}}\right), 75.0\left(\mathrm{C}-4_{\mathrm{E}}\right), 74.9$ $(\mathrm{PhCH}), 74.7\left(\mathrm{C}-3_{\mathrm{D}}\right), 74.5\left(2 \mathrm{C}, \mathrm{C}-2_{\mathrm{E}}, \mathrm{C}-3_{\mathrm{E}}\right), 74.0(\mathrm{PhCH}), 73.3(\mathrm{C}-$ $\left.3_{\mathrm{B}}\right), 72.8(2 \mathrm{C}, 2 \mathrm{PhCH}), 72.7(\mathrm{PhCH}), 72.1\left(\mathrm{C}-3_{\mathrm{A}}\right), 71.9(\mathrm{PhCH})$, $71.1\left(\mathrm{C}-4_{\mathrm{D}}\right), 70.5(\mathrm{PhCH}), 69.4\left(\mathrm{C}-5_{\mathrm{D}}\right), 68.6\left(\mathrm{C}-6_{\mathrm{E}}\right), 68.3\left(\mathrm{C}-4_{\mathrm{A}}\right)$, $66.1\left(\mathrm{OCH}_{2}\right), 65.8\left(\mathrm{C}-6_{\mathrm{C}}\right), 64.6\left(\mathrm{C}-5_{\mathrm{A}}\right), 64.9\left(\mathrm{C}-6_{\mathrm{A}}\right), 63.3\left(\mathrm{C}-5_{\mathrm{E}}\right), 62.3$ $\left(\mathrm{C}-5_{\mathrm{B}}\right), 54.8\left(\mathrm{C}-2_{\mathrm{A}}\right), 50.4\left(\mathrm{NCH}_{2}\right), 26.0\left(\mathrm{CCH}_{3}\right), 21.2,20.9,20.8$ $\left(3 \mathrm{COCH}_{3}\right), 15.9,15.8\left(2 \mathrm{CCH}_{3}\right)$; MALDI-MS: $1947.7[\mathrm{M}+\mathrm{Na}]^{+}$; anal. calcd for $\mathrm{C}_{106} \mathrm{H}_{116} \mathrm{~N}_{4} \mathrm{O}_{30}$ (1926.06): C, 66.10; $\mathrm{H}, 6.07 \%$; found: $\mathrm{C}, 66.00 ; \mathrm{H}, 6.20 \%$.

\section{2-Aminoethyl $O$-(4,6-O-[(R)-(1-sodium carboxylate)ethylidene $]$ - $\alpha$-D-galactopyranosyl)-(1 $\rightarrow 3)$-( $\alpha$-L-fucopyranosyl)-(1 $\rightarrow 6)-(\alpha-$ D-galactopyranosyl)-(1 $\rightarrow 3)$-( $\alpha$-L-fucopyranosyl)-(1 $\rightarrow 3)-2$ - acetamido-2-deoxy- $\beta$-D-glucopyranoside (1)}

To a solution of compound 15 (300 $\mathrm{mg}, 0.23 \mathrm{mmol})$ in ${ }^{n}$ butanol $(15 \mathrm{~mL})$ was added ethylene diamine $(0.3 \mathrm{~mL})$ and the mixture was stirred at $90{ }^{\circ} \mathrm{C}$ for $10 \mathrm{~h}$. The solvents were removed under reduced pressure, the crude product was dissolved in acetic anhydride $(2 \mathrm{~mL})$ and pyridine $(2 \mathrm{~mL})$ and the solution was kept at room temperature for $1 \mathrm{~h}$. The solvents were removed under reduced pressure to give the acetylated product that was passed through a short pad of silica gel with EtOAc $(50 \mathrm{~mL})$ as eluent. To a solution of the acetylated product in $\mathrm{CH}_{3} \mathrm{OH}(10 \mathrm{~mL})$ was added $20 \% \mathrm{Pd}(\mathrm{OH})_{2}-\mathrm{C}(100 \mathrm{mg})$ and the reaction mixture was stirred under a positive pressure of hydrogen at room temperature for $15 \mathrm{~h}$. The reaction mixture was filtered through a Celite bed, washed with $\mathrm{CH}_{3} \mathrm{OH}(30 \mathrm{~mL})$ and concentrated. A solution of the crude product in $0.1 \mathrm{M} \mathrm{CH}_{3} \mathrm{ONa}(10 \mathrm{~mL})$ was stirred at room temperature for $3 \mathrm{~h}$, then few drops of water was added and further stirred for another $8 \mathrm{~h}$. The reaction mixture was neutralized with Dowex 50W X8 $\left(\mathrm{H}^{+}\right)$, filtered, and concentrated to give the crude product that was purified by gel chromatography using Sephadex $\mathrm{LH}-20$ using $\mathrm{CH}_{3} \mathrm{OH}-\mathrm{H}_{2} \mathrm{O}(3: 1)$ as eluant to give $1(120 \mathrm{mg}, 54 \%)$. White powder; $[\alpha]_{\mathrm{D}}^{25}+10.2\left(c 1.0, \mathrm{H}_{2} \mathrm{O}\right)$; ${ }^{1} \mathrm{H}$ NMR (500 MHz, $\left.\mathrm{D}_{2} \mathrm{O}\right): \delta 5.08\left(\mathrm{~d}, J=3.5 \mathrm{~Hz}, 1 \mathrm{H}, \mathrm{H}-1_{\mathrm{E}}\right), 5.05$ (d, $\left.J=4.0 \mathrm{~Hz}, 1 \mathrm{H}, \mathrm{H}-1_{\mathrm{C}}\right), 4.89\left(\mathrm{~d}, J=3.5 \mathrm{~Hz}, 1 \mathrm{H}, \mathrm{H}-1_{\mathrm{B}}\right), 4.78(\mathrm{~d}, J=$ $\left.4.0 \mathrm{~Hz}, 1 \mathrm{H}, \mathrm{H}-1_{\mathrm{D}}\right), 4.41\left(\mathrm{~d}, J=8.5 \mathrm{~Hz}, 1 \mathrm{H}, \mathrm{H}-1_{\mathrm{A}}\right), 4.18(\mathrm{~d}, J=$ $\left.7.0 \mathrm{~Hz}, 1 \mathrm{H}, \mathrm{H}-5_{\mathrm{B}}\right), 4.12\left(\mathrm{t}, J=6.0 \mathrm{~Hz}\right.$ each, $\left.1 \mathrm{H}, \mathrm{H}-5_{\mathrm{C}}\right), 4.09(\mathrm{~d}, J=$ $\left.3.5 \mathrm{~Hz}, 1 \mathrm{H}, \mathrm{H}-4_{\mathrm{E}}\right), 4.00-3.85\left(\mathrm{~m}, 4 \mathrm{H}, \mathrm{H}-3_{\mathrm{E}}, \mathrm{H}-4_{\mathrm{C}}, \mathrm{H}-4_{\mathrm{B}}, \mathrm{H}-5_{\mathrm{D}}\right)$, 3.84-3.78 (m, 5H, H-2 $\left., \mathrm{H}-2_{\mathrm{E}}, \mathrm{H}-3_{\mathrm{D}}, \mathrm{H}-5_{\mathrm{E}}, \mathrm{OCH}\right), 3.77-3.70(\mathrm{~m}$, $\left.10 \mathrm{H}, \mathrm{H}-2_{\mathrm{A}}, \mathrm{H}-2_{\mathrm{B}}, \mathrm{H}-2_{\mathrm{C}}, \mathrm{H}-3_{\mathrm{B}}, \mathrm{H}-3_{\mathrm{C}}, \mathrm{H}-4_{\mathrm{D}}, \mathrm{H}-6_{\mathrm{abE}}, \mathrm{H}-6_{\mathrm{aA}}, \mathrm{H}-6_{\mathrm{aC}}\right)$, 3.69-3.58 (m, $\left.2 \mathrm{H}, \mathrm{H}-4_{\mathrm{A}}, \mathrm{OCH}\right), 3.57-3.50\left(\mathrm{~m}, 1 \mathrm{H}, \mathrm{H}-3_{\mathrm{A}}\right), 3.48-$ $3.32\left(\mathrm{~m}, 3 \mathrm{H}, \mathrm{H}-5_{\mathrm{A}}, \mathrm{H}-6_{\mathrm{bA}}, \mathrm{H}-6_{\mathrm{bC}}\right), 3.12-3.0\left(\mathrm{~m}, 2 \mathrm{H}, \mathrm{NCH}_{2}\right), 1.88$ (s, $\left.3 \mathrm{H}, \mathrm{NHCOCH}_{3}\right), 1.43\left(\mathrm{~s}, 3 \mathrm{H}, \mathrm{CCH}_{3}\right), 1.03-1.01\left(\mathrm{~m}, 6 \mathrm{H}, 2 \mathrm{CCH}_{3}\right)$; ${ }^{13} \mathrm{C}$ NMR (125 MHz, $\left.\mathrm{D}_{2} \mathrm{O}\right): \delta 176.09(\mathrm{COOH}), 174.0\left(\mathrm{NHCOCH}_{3}\right)$, $101.5\left(\mathrm{C}-1_{\mathrm{A}}\right), 100.7\left(2 \mathrm{C}, \mathrm{C}-1_{\mathrm{C}}, \mathrm{C}-1_{\mathrm{E}}\right), 100.6(\mathrm{CCOOH}), 99.8\left(\mathrm{C}-1_{\mathrm{D}}\right)$, $98.4\left(\mathrm{C}-1_{\mathrm{B}}\right), 80.0\left(\mathrm{C}-3_{\mathrm{A}}\right), 78.9\left(\mathrm{C}-3_{\mathrm{B}}\right), 78.2\left(\mathrm{C}-4_{\mathrm{D}}\right), 75.8\left(\mathrm{C}-5_{\mathrm{A}}\right), 71.7$ $\left(2 \mathrm{C}, \mathrm{C}-3_{\mathrm{D}}, \mathrm{C}-4_{\mathrm{E}}\right), 71.4\left(2 \mathrm{C}, \mathrm{C}-4_{\mathrm{B}}, \mathrm{C}-4_{\mathrm{C}}\right), 69.7\left(\mathrm{C}-5_{\mathrm{C}}\right), 69.4\left(\mathrm{C}-4_{\mathrm{A}}\right)$, $69.2\left(\mathrm{C}-3_{\mathrm{C}}\right), 68.6\left(\mathrm{C}-2_{\mathrm{C}}\right), 68.5\left(\mathrm{C}-2_{\mathrm{E}}\right), 68.4\left(\mathrm{C}-3_{\mathrm{E}}\right), 67.9\left(\mathrm{C}-2_{\mathrm{D}}\right), 66.8$ $\left(2 \mathrm{C}, \mathrm{C}-5_{\mathrm{B}}, \mathrm{C}-5_{\mathrm{D}}\right), 66.6\left(\mathrm{C}-2_{\mathrm{B}}\right), 66.5\left(\mathrm{C}-6_{\mathrm{C}}\right), 65.9\left(\mathrm{C}-6_{\mathrm{E}}\right), 64.9\left(\mathrm{C}-6_{\mathrm{A}}\right)$, $62.9\left(\mathrm{C}-5_{\mathrm{E}}\right), 60.6\left(\mathrm{OCH}_{2}\right), 55.0\left(\mathrm{C}-2_{\mathrm{A}}\right), 39.4\left(\mathrm{NCH}_{2}\right), 25.1\left(\mathrm{CCH}_{3}\right)$, $22.2\left(\mathrm{COCH}_{3}\right)$, 15.5, $15.2\left(\mathrm{CCH}_{3}\right)$; MALDI-MS: $972.3[\mathrm{M}]^{+}$; anal. calcd for $\mathrm{C}_{37} \mathrm{H}_{61} \mathrm{~N}_{2} \mathrm{NaO}_{26}$ (972.86): C, 45.68; $\mathrm{H}, 6.32 \%$; found: $\mathrm{C}$, 45.50; H, 6.45\%. 


\section{Conclusions}

In conclusion, a concise convergent strategy has been developed for the synthesis of the pyruvate acetal containing pentasaccharide repeating unit of the cell wall O-antigen of E. coli O156 in excellent yield. Application of stereoselective $[2+3]$ block glycosylation, achievements of several $\alpha$-glycosidic linkages, use of $\mathrm{HClO}_{4}-\mathrm{SiO}_{2}$, a cheap and stable solid acid in the glycosylation, preparation of pyruvic acid acetal using pyruvate dithioacetal under glycosylation condition, attachment of 2aminoethyl linker at the reducing end for easy connectivity with an appropriate protein or aglycone are important features of the synthetic scheme. All glycosylation steps are high yielding with excellent stereoselectivity.

\section{Conflicts of interest}

There are no conflicts to declare.

\section{Acknowledgements}

A. S. thanks CSIR, New Delhi for providing Senior Research Fellowship. The work is supported by SERB, New Delhi (Project No. EMR/2015/000282 dated 17.09.2015) (AKM) and Bose Institute.

\section{Notes and references}

1 J. T. Watson, M. Gayer and M. A. Connolly, Emerging Infect. Dis., 2007, 13, 1-5.

2 V. Curtis, S. Cairncross and R. Yonli, Trop. Med. Int. Health, 2000, 5, 22-32.

3 G. Gavazzi, F. Herrmann and K.-H. Krause, Clin. Infect. Dis., 2004, 39, 83-91.

4 O. Müller and M. Krawinkel, Can. Med. Assoc. J., 2005, 173, 279-286.

5 B. M. Lund and S. J. O'Brien, Foodborne Pathog. Dis., 2011, 8, 961-973.

6 F. Jafari, L. Shokrzadeh, M. Hamidian, S. SalmanzadehAhrabi and M. R. Ali, Jpn. J. Infect. Dis., 2008, 61, 269-273.

7 G. O. Canny and B. A. McCormick, Infect. Immun., 2008, 76, 3360-3373.

8 J. P. Nataro and J. B. Kaper, Clin. Microbiol. Rev., 1998, 11, 142-201.

9 B. Köves and B. Wullt, Eur. Urol., Suppl., 2016, 15, 88-94.

10 J. M. Rhodes, Gut, 2007, 56, 610-612.

11 R. E. Besser, S. M. Lett, J. T. Weber, M. P. Doyle, T. J. Barrett, J. G. Wells and P. M. Griffin, J. Am. Med. Assoc., 1993, 269, 2217-2220.

12 F. E. Preston, R. G. Malia, M. J. Sworn and E. K. Blackburn, J. Clin. Pathol., 1973, 26, 120-125.

13 M. A. Croxen, R. J. Law, R. Scholz, K. M. Keeney, M. Wlodarska and B. B. Finlay, Clin. Microbiol. Rev., 2013, 26, 822-880.

14 J. C. Paton and A. W. Paton, Clin. Microbiol. Rev., 1998, 11, 450-479.
15 J. Y. Lim, J. W. Yoon and C. J. Hovde, J. Microbiol. Biotechnol., 2010, 20, 5-14.

16 N. Allocati, M. Masulli, M. F. Alexeyev and C. D. Ilio, Int. J. Environ. Res. Public Health, 2013, 10, 6235-6254.

17 J. M. Bosilevac and M. Koohmaraie, Appl. Environ. Microbiol., 2011, 77, 2103-2112.

18 I. Lerouge and J. Vanderleyden, FEMS Microbiol. Rev., 2002, 26, 17-47.

19 (a) Carbohydrate based vaccines, ed. R. Roy, Oxford University Press, Oxford, 2008; (b) J. J. Mond, A. Lees and C. M. Snapper, Annu. Rev. Immunol., 1995, 13, 655-692.

20 (a) R. D. Astronomo and D. R. Burton, Nat. Rev. Drug Discovery, 2010, 9, 308-324; (b) M. Cavallari and G. De Libero, Vaccines, 2017, 5, 4, DOI: 10.3390/vaccines5010004.

21 Z. Duan, S. N. Senchenkova, X. Guo, A. V. Perepelov, A. S. Shashkov, B. Liu and Y. A. Knirel, Carbohydr. Res., 2016, 430, 24-28.

22 A. Chakkumkal, S. Benjamin, L. P. Claney and P. H. Seeberger, Chem. Biol., 2014, 21, 38-50.

23 (a) V. Pozsgay, Curr. Top. Med. Chem., 2008, 8, 126-140; (b) A. Hölemann and P. H. Seeberger, Curr. Opin. Biotechnol., 2004, 15, 522-555.

24 A. K. Chakraborti and R. Gulhane, Chem. Commun., 2003, 1896-1897.

25 C. Mukherjee and A. K. Misra, Synthesis, 2007, 683-692.

26 B. Mukhopadhyay, S. V. Maurer, N. Rudolph, R. M. van Well, D. A. Russell and R. A. Field, J. Org. Chem., 2005, 70, 90599062.

27 G. Agnihotri and A. K. Misra, Tetrahedron Lett., 2006, 47, 8493-8497.

28 P. K. Mandal, Synthesis, 2015, 47, 836-844.

29 T. Ziegler, Carbohydr. Res., 1994, 262, 195-212.

30 J. Lindberg, P. Stralfors and P. Konradsson, Tetrahedron, 2002, 58, 4245-4254.

31 Y. Hua, Y. Du, G. Yu and S. Chu, Carbohydr. Res., 2004, 339, 2083-2090.

32 S. Figueroa-Perez and R. R. Schmidt, Carbohydr. Res., 2000, 328, 95-102.

33 G. Zemplen, Ber. Dtsch. Chem. Ges., 1926, 59, 1254-1266.

34 G. Agnihotri and A. K. Misra, Tetrahedron Lett., 2006, 47, 3653-3658.

35 T. Ogawa and H. Yamamoto, Agric. Biol. Chem., 1985, 49, 475-482.

36 O. Kanie, Y. Ito and T. Ogawa, J. Am. Chem. Soc., 1994, 116, 12073-12074.

37 K. Bock and C. Pederson, J. Chem. Soc., Perkin Trans. 2, 1974, 293-297.

38 D. Crich and H. Li, J. Org. Chem., 2002, 67, 4640-4646.

39 A. Liptak, I. Bajza, J. Kerekgyarto, J. Hajko and L. Szilagyi, Carbohydr. Res., 1994, 253, 111-120.

40 P. A. J. Gorin, M. Mazurek, H. S. Duarte, M. Iacomini and J. H. Duarte, Carbohydr. Res., 1982, 100, 1-15.

41 J. S. Debenham, R. Madsen, C. Roberts and B. Fraser-Reid, J. Am. Chem. Soc., 1995, 117, 3302-3303.

42 W. M. Pearlman, Tetrahedron Lett., 1967, 8, 1663-1664. 